\title{
Reconstruction, Binding Theory, and the Interpretation of Chains
}

\author{
Danny Fox
}

This article investigates interactions between the scope of QPs and the restrictions imposed by binding theory. It presents new evidence that Condition $\mathrm{C}$ applies at (and only at) LF and demonstrates that this condition can serve as a powerful tool for distinguishing among various claims regarding the nature of LF and the inventory of semantic mechanisms. The conclusions reached are these: (1) Scope reconstruction is represented in the syntax (semantic type-shifting operations are very limited). (2) A-chains have the following properties: (a) Scope reconstructionresults from deleting the head of the chain and interpreting a copy at the tail. (b) Non-scope-reconstruction results from interpreting the head of the chain with a copy of the restrictor at the tail (unless this option is impossible, as in antecedent-containeddeletion, in which case the copy is changed to a variable as in standard notations). (c) VP adjunction is an intermediate landing site. (3) A-chains are different in a way that at the moment requires a stipulative distinction.

Keywords: scope, reconstruction, chains, binding theory, semantic type shifting, copy theory of movement, successive-cyclic movement, economy

In the early days of generative grammar, overt movement was characterized as involving a disparity between the position at which an item is interpreted and the position at which it is overtly realized. However, since the 1960s it has been known that this is not strictly true. Although certain interpretive properties of a moved constituent are determined in the base position, other properties can be determined at the landing site. ${ }^{1}$ Specifically, although aspects of interpretation having to do with predicate-argument relations-with $\theta$-assignment-are determined at the base position, aspects of interpretation having to do with scope and variable binding are determined at the landing site (see Chomsky 1977 and references therein). ${ }^{2}$ This has led to a different view of the

This article was presented in the LF reading group at MIT (September 1996) and at the Tübingen Reconstruction Workshop (May 1997). I wish to thank the participants in both events. Thanks also to Jonathan Bobaljik, Marie Claude Boivin, Kai von Fintel, Martin Hackl, Howard Lasnik, Orin Percus, the $L I$ reviewers, and especially to Gennaro Chierchia, Noam Chomsky, Irene Heim, Jon Nissenbaum, David Pesetsky, and Uli Sauerland. After presenting this material, I learned that Maribel Romero had independently developed many of the arguments in sections 2 and 3.

${ }^{1}$ Some suggestions that this is the case were already present in Chomsky 1957. For a collection of many of the original arguments, see Jackendoff 1972.

${ }^{2}$ Other aspects of interpretation that are affected by movement (e.g., topic/focus) are outside the scope of this article. 
grammar's architecture. Under this view, overt displacement affects meaning as well as sound. ${ }^{3}$ Structures involving movement serve as the input for both the conceptual and the articulatory systems. In the articulatory system, the base position is ignored. However, in the conceptual system, both positions are taken into account, and the interpretive properties are distributed between them according to the division outlined above.

This new picture itself had to be revised given the observation that the effects of movement on scope and variable binding are not obligatorily present; there are cases where the semantic effects of movement (predicted by the new picture) are "undone" (henceforth, cases of scope reconstruction). The attempts to deal with scope reconstruction, and the resulting accommodation to the picture, can be divided into two types. The first type of accommodation assumes that scope reconstruction is the outcome of semantic procedures. What is claimed is that the interpretive principles can deal with movement chains in at least two ways. One way results in an interpretation in which scope is determined at the base position; the other, in an interpretation in which scope is determined at the landing site. The second type of accommodation assumes that scope reconstruction is already determined in the syntax. In other words, it is claimed that the structures that serve as the input to semantic interpretation (the structures of LF) determine whether or not there is scope reconstruction.

In this article I argue that scope reconstruction is syntactic. In particular, Condition $\mathrm{C}$ of binding theory will serve to demonstrate that (at the level at which this condition applies) the position of a scope-bearing element differs depending on whether or not there is scope reconstruction. The semantic approach to scope reconstruction cannot account for this correlation. However, it follows straightforwardly from the syntactic approach under the assumption that binding theory is sensitive to LF positions.

Once the argument in favor of the syntactic approach is presented, I spell out the nature of the syntactic mechanisms that yield reconstruction. I argue for a version of the copy theory of movement suggested by Chomsky (1993) on the basis of data from antecedent-containeddeletion. Under this version, A-movement leaves a copy at the tail of the chain. This copy can be reduced to a standard variable only when necessary. The result is that $\mathrm{A}$-movement can bleed Condition $\mathrm{C}$ if (a) the copy at the tail is reduced or (b) an adjunct is added after movement (Lebeaux 1988). Syntactic reconstruction is the result of the elimination of the head of the chain, which is impossible when (a) or (b) obtains (and thus is inconsistent with the bleeding of Condition C).

The structure of the article is as follows. In section 1 I will elaborate on the semantic and syntactic approaches to the phenomenon of scope reconstruction and establish that the syntactic approach predicts a specific correlation between this phenomenon and Condition $\mathrm{C}$ effects. In sections 2 and 3 I will demonstrate that the prediction is borne out for $\bar{A}$ - and A-movement, respectively. In section $4 \mathrm{I}$ will discuss the ramifications of the arguments in favor of syntactic reconstruction for the status of the semantic mechanisms of type shifting. In section 5 I will discuss the ramifications for the architecture of the grammar and, more specifically, for the place

\footnotetext{
${ }^{3}$ This new view (together with the postulation of traces) paved the road for an account of scopal ambiguity in terms of movement operations that are invisible to phonology (such as Quantifier Raising $(\mathrm{QR})$ ).
} 
of binding theory therein. The correlation between scope and Condition $\mathrm{C}$ will obviously argue that Condition $\mathrm{C}$ is sensitive to LF positions-in other words, that this condition applies also at LF. I will further specify, recapitulating ideas from Chomsky 1993 and Fox 1995a, how the correlation fits into a broader picture in which binding theory applies only at LF. This discussion will provide the outlines of the theory of syntactic scope reconstruction that I present in sections 6 and 7.

\section{Semantic versus Syntactic Accounts of Scope Reconstruction}

It is well known that overt movement can affect scope. This has been established in many ways. The simplest examples are probably from scrambling languages (see Hoji 1985). ${ }^{4}$ However, English examples such as (1) also illustrate the point. ${ }^{5}$ In (1b) the embedded object is overtly displaced, and the result of this displacement allows it to receive wide scope relative to another scope-bearing element (the existential quantifier). This scope relation would have been impossible without overt movement, as demonstrated in (1a). ${ }^{6}$

(1) a. John seems to a (\#different) teacher [t to be likely to solve every one of these problems].

$(\exists>\forall ; * \forall>\exists)^{7}$

b. [Every one of these problems] seems to a (different) teacher [t to be likely t to be solved t by John].

\footnotetext{
${ }^{4}$ For some reason that is not completely clear to me, the ability to affect scope is restricted to short-distance scrambling. See Tada 1993.

${ }^{5}$ The English examples that are standardly invoked to make this point are simpler. For example, Jackendoff (1972) argues that movement affects scope on the basis of contrasts such as that between (ia) and (ib). In (ia) many prefers to have wide scope relative to negation; in (ib) the preference goes in the other direction.
}

(i) a. Many arrows didn't hit the target.

b. The target wasn't hit by many arrows.

The examples demonstrate that overt movement affects interpretive preferences. However, they do not demonstrate that overt movement yields interpretations that would be unavailable otherwise. Given the availability of covert scope-shifting operations, both sentences in (i) are ambiguous. For us to demonstrate that scope is affected by movement, overt movement must do something that QR cannot do. In other words, the demonstration depends on the existence of constraints that apply to QR and not to overt movement. In (1) the constraint might follow from an account of the "clause-boundedness" of QR. There might be additional constraints on specific types of quantifiers (e.g., monotone decreasing; see McCawley 1988:618-628) that will yield a similar argument. (See Liu 1990, Beghelli 1993, and Beghelli and Stowell 1995 for a detailed investigation of the properties of different quantificational elements.)

${ }^{6}$ A similar point can be made with regard to variable binding. In (ia) the universal quantifier cannot bind a variable that is outside of its scope. In (ib) overt movement gives the quantifier wider scope and allows it to bind the variable.

(i) a. *The teacher is expected by his ${ }_{1}$ mother [t to encourage every boy $y_{1}$.

b. Every boy $y_{1}$ is expected by his ${ }_{1}$ mother [ $t$ to be encouraged $t$ by the teacher].

${ }^{7}$ That the universal quantifier cannot take wide scope is shown by the ungrammaticality of (1a) when different receives a bound interpretation, as in A different guard is standing on top of every building. It is further demonstrated by cases in which the alternative scope relation results in an interpretation that is cognitively anomalous: \#This soldier seems to someone to be likely to die in every battle; \#The ball seems to a boy to be under every shell (cf. Every shell seems to a (different) boy to be over the ball). 
However, overt movement does not obligatorily affect scope. This has been known at least since May 1977. Consider constructions that involve successive-cyclic raising, such as those in (2). In these constructions the scope of the moved quantifier can be affected by movement. However, it need not be; the scope may be construed in the base position or in any of the intermediate landing sites.

(2) a. Someone from New York is very likely t to win the lottery.

b. Someone from New York seems t to be very likely $t^{\prime}$ to win the lottery.

c. Many soldiers seem to be very likely $t^{\prime}$ to die in the battle.

Take (2a), which is two-ways ambiguous. One interpretation results when the quantifier takes scope in the final landing site. For the sentence to be true under this interpretation, there must be a person from New York who is very likely to win the lottery (e.g., a person who bought enough tickets to make winning a likely outcome). Under the second interpretation, in which the quantifier has scope in the position of $t$, the truth conditions are much less demanding; they merely require that there be enough ticket buyers from New York to make it likely that the city would yield a winner.

The examples in (2) demonstrate the availability of scope reconstruction. This availability can be further demonstrated in ways that are not based on any assumptions regarding the interpretation of modality. The demonstration is based on the constructions in (3) and (4), partially due to Lebeaux (1994). ${ }^{8}$

(3) a. [At least one soldier $]_{1}$ seems (to Napoleon) [ $\mathrm{t}_{1}$ to be likely to die in every battle].

b. [At least one soldier $]_{1}$ seems to himself ${ }_{1}\left[\mathrm{t}_{1}\right.$ to be likely to die in every battle].

c. [At least one soldier] $]_{1}$ seems to his $_{1}$ commanders [ $\mathrm{t}_{1}$ to be likely to die in every battle].

(4) a. One soldier is expected (by Napoleon) [t to die in every battle].

b. One soldier ${ }_{1}$ is expected by his $\mathrm{s}_{1}$ commander [ $\mathrm{t}_{1}$ to die in every battle].

In the (a) sentences the universal quantifier in the embedded clause can take scope over the matrix subject $(\forall>\exists)$. In other words, the sentences can be interpreted in such a way that the soldiers can vary with the battles. They can also receive an interpretation in which the matrix subject takes wide scope $(\exists>\forall)$. This is the implausible interpretation that asserts the existence of a single soldier who is expected to die in all of the battles.

One could imagine that the source of the ambiguity in the (a) sentences is the availability of long-distance Quantifier Raising (QR). The universal quantifier can move by QR over the existential quantifier, and the optionality of this movement, one might think, is the cause of the ambiguity.

${ }^{8}$ Aoun (1982) notes similar data, attributing them to Luigi Rizzi. I have changed Lebeaux's examples slightly. The first change involves the choice of lexical items. I tried to make the interpretation resulting from wide scope for the matrix subject $(\exists>\forall)$ conflict with world knowledge. This change makes the unavailability of the alternative scopal relation in the (b) and (c) sentences $(\forall>\exists$ ) very striking. The second change is the addition of (3c) and (4b), which contain a bound pronoun (rather than a reflexive) within the dative PP (see also Hornstein 1995:160). This change is meant to explain why I do not draw the same conclusions that Lebeaux does (see footnote 9). 
However, this is most likely not the case. The (b) and (c) sentences show that the ambiguity in the (a) sentences requires scope reconstruction. If QR were sufficient to yield the ambiguity in the (a) sentences, we would expect to find the same kind of ambiguity in the (b) and (c) sentences. However, the latter sentences are unambiguous. Their meaning is restricted to the implausible interpretation that results from assigning wide scope to the existential quantifier. Although this restriction is unaccounted for under the assumption that QR alone is the source of the ambiguity in the (a) sentences, the assumption that scope reconstruction is needed accounts for it straightforwardly. In the (b) and (c) sentences, the existential quantifier must bind a variable in a position outside its scope as determined by scope reconstruction. Hence, scope reconstruction is impossible. ${ }^{9}$ We must assume that the $(\forall>\exists$ ) interpretation of the (a) sentences results from a combination of scope reconstruction and short-distance QR. The matrix subject receives scope in the position of $t$ and the universal quantifier receives scope above this position (via QR).

Consider next the contrast between the sentences in (5) and (6). Some speakers find the (a) sentences slightly marginal. This is accounted for by weak crossover (WCO) under the assumption that QR involves A-movement. However, the (b) sentences are acceptable. This contrast is explained if we assume that $\mathrm{QR}$ is not necessary for the universal quantifier to have wide scope. This assumption, in turn, is explained by the availability of scope reconstruction in the (b) sentences.

(5) a. ??[Someone from his ${ }_{1}$ class $]_{2}$ shouted to every professor ${ }_{1}\left[\mathrm{PRO}_{1}\right.$ to be careful]. b. [Someone from his $s_{1}$ class $]_{2}$ seems to every professor ${ }_{1}\left[\mathrm{t}_{2}\right.$ to be a genius].

(6) a. ??[His father $_{2}$ wrote to every boy $\left[\mathrm{PRO}_{1}\right.$ to be a genius].

b. $\left[\mathrm{His}_{1} \text { father }\right]_{2}$ seems to every boy $_{1}\left[\mathrm{t}_{2}\right.$ to be a genius].

\subsection{Syntactic Accounts of Scope Reconstruction}

Under the syntactic accounts of scope reconstruction, the ambiguous sentences in (2)-(4) are disambiguated at LF. Under one disambiguation the Quantifier Phrase (QP) is in its surface position and binds a variable in the trace position. Under other disambiguations the QP is in one of the intermediate trace positions (alternatively, in a position that binds such positions ${ }^{10}$ ). This is illustrated with the two LF structures of (2a) given in (7).

(7) $\mathrm{LF}_{1}:$ [someone from $\left.\mathrm{NY}\right]_{1}$ is very likely $\left[\mathrm{t}_{1}\right.$ to win the lottery] $\mathrm{LF}_{2}$ : $\quad$ is very likely [[someone from NY] to win the lottery]

This syntactic reconstruction could be achieved by various mechanisms. Among these mechanisms is Quantifier Lowering (QL), suggested for A-movement by May (1977), and the copy theory of movement, suggested for A-reconstruction by Chomsky (1993) and extended by many

\footnotetext{
${ }^{9}$ Lebeaux (1994) draws a more radical conclusion. Given the unavailability of $(\forall>\exists)$ in (3b), he concludes that Condition A of binding theory must be satisfied at LF. Although the conclusion seems plausible to me, I do not think the example bears on it. All we can argue for on the basis of (3b), as is perhaps clearer from (3c) and (4b), is that $(\forall>\exists$ ) in the (a) sentences requires scope reconstruction. The facts follow with the addition of a (virtual) tautology that a quantifier cannot bind a variable outside of its scope.

${ }^{10}$ Such binding could result from a QL operation as in May 1977. See Chomsky 1995:327.
} 
to A-movement (see, e.g., Hornstein 1995). However, at the moment I will abstract away from the details of the implementation (see sections 6 and 7). What matters right now is the property that all the syntactic accounts share: they all assume that scope reconstruction involves an LF structure in which the QP is literally in the reconstructed position. This account of scope reconstruction extends straightforwardly to all the cases discussed, including the cases of variable binding. In other words, this account straightforwardly explains the fact that the (b) sentences in (5) and (6) do not show a WCO effect.

\subsection{Semantic Accounts of Scope Reconstruction}

Semantic accounts assume that syntactic reconstruction is not necessary for scope reconstruction. (See Chierchia 1995b, Cresti 1995, and Rullmann 1995.) In other words, they assume that there is a semantic mechanism that yields the two interpretations of sentences such as (2a) from a structure with no syntactic reconstruction such as $\mathrm{LF}_{1}$ in (7). The existence of such a semantic mechanism is tacitly assumed in the scope principle suggested by Aoun and Li (1993) and explored by Frey (1989), ${ }^{11}$ Kitahara (1994), and Krifka (1998), among others.

The semantic nature of this mechanism has been developed explicitly within frameworks that assume that a semantic type is associated with each syntactic expression. A further assumption is that the sister of a moved constituent is interpreted as a function that can be expressed with lambda abstraction over a variable in the trace position. The question is, of course, "A variable of what type?" The assumption is that in cases in which a QP undergoes movement, the variable can range either over individuals (i.e., be interpreted as a variable of type $e$ ) or over generalized quantifiers - that is, second-order predicates (i.e., be interpreted as a variable of type $\langle$ et,t $\rangle$ ). For an incomplete illustration, consider the two options for interpreting $\mathrm{LF}_{1}$. (For a more complete discussion, see Heim and Kratzer, forthcoming.) These two options are represented in (8), where $x$ ranges over individuals and $Q$ ranges over generalized quantifiers.

(8) a. [someone from NY] $\lambda x$ (is very likely [ $x$ to win the lottery])

b. [someone from NY] $\lambda \mathrm{Q}$ (is very likely [Q to win the lottery])

In (8a), where the variable is of type $e$, the sister of the moved QP is interpreted as a function from individuals to truth values (type et). Since the moved QP is of type $\langle$ et, $\mathrm{t}$, the QP takes its sister as its argument. It is easy to see that the resulting interpretation is one in which the existential quantifier has scope over the modal verb. In (8b) the sister of the quantifier is interpreted as a function from generalized quantifiers to truth values (type $\langle\langle e t, t\rangle, t\rangle)$. In this case the QP is the argument of its sister, and it is easy to see (once we consider lambda conversion) that the modal verb receives wide scope. ${ }^{12}$

${ }^{11}$ Thanks to Uli Sauerland for conveying to me the contents of this work (in German), which I unfortunately am unable to read.

${ }^{12}$ Note that this semantic account, just like the syntactic account, captures straightforwardly the virtual tautology that scope reconstruction to a position of a trace is incompatible with the binding of a variable outside the c-command domain of this trace. For example, this account is on a par with the syntactic account with respect to the contrasts in (3) and (4). See footnotes 8 and 9. 
The semantic account of scope reconstruction extends straightforwardly to all the cases discussed except for the cases of variable binding via reconstruction (the (b) sentences in (5) and (6)). A few further assumptions need to be made in order for semantic reconstruction to allow for variable binding (into the reconstructed element). I will not go over these assumptions and instead refer the reader to Engdahl 1986, Sternefeld 1997, Chierchia 1995a, and Sharvit 1997.

\subsection{Distinguishing the Two Accounts via Condition C}

Consider the structural configuration in (9), in which linear precedence represents c-command. If Condition $\mathrm{C}$ is sensitive to LF structures, the syntactic account predicts that scope reconstruction should be impossible in (9). This prediction is stated in (10).

(9) $\left[\mathrm{Q} \text { P . r-expression }{ }_{1} \ldots\right]_{2} \ldots \operatorname{pronoun}_{1} \ldots \mathrm{t}_{2}$

(10) Scope reconstruction feeds Condition $C$

Scope reconstruction should be impossible in the structural configuration in (9).

In order for this prediction to follow under the semantic account of scope reconstruction, one would have to assume that Condition $\mathrm{C}$ makes reference to the semantic type of traces and that the LF structure in (9) is ruled out if and only if the semantic type of the trace is $\langle$ et,t . (See Sternefeld 1997.) This, however, cannot be considered an explanation. The necessary assumption is a post hoc stipulation that does not tell us why things are the way they are. In particular, it would be just as plausible to make the opposite assumption (i.e., that Condition $\mathrm{C}$ rules out (9) when the semantic type of the trace is $e$ ), from which it would follow that scope reconstruction is obligatory in (9). ${ }^{13}$

Under the syntactic account of scope reconstruction, (10) is explained. Condition $\mathrm{C}$ receives the simple definition based on constructions for which the structural analysis is not debated (constructions without movement). Under the natural assumption that an interpretive principle (such as binding theory) is sensitive to LF structures, (10) follows. Therefore, if we can show that the prediction holds, we will have an argument in tandem for both the syntactic account and the assumption that Condition $\mathrm{C}$ applies at LF. In the following sections I will demonstrate that the prediction does hold and that we do have the argument. ${ }^{14}$

${ }^{13}$ Gennaro Chierchia (personal communication; attributing the idea to work in progress by Yael Sharvit) points out that the correlation in (10) could follow from semantic reconstruction if (certain) Condition C effects are viewed as the results of a preference for variable binding over coreference (as in Reinhart's Rule I; see Grodzinsky and Reinhart 1993). In particular, he suggests that if the semantic type of the trace yields a "reconstructed" interpretation, variable binding is possible and thus coreference is ruled out. Although this is conceivable, I think that many questions need to be answered before we know whether this is a real alternative. For example, what is the status of a basic semantic type such as $\langle e t, t\rangle$, which allows for scope reconstruction with no variable binding reconstruction (see (8b))? It is possible for semantic reconstruction to predict that Condition $\mathrm{C}$ will be affected by variable binding reconstruction-but is there a nonstipulative way to predict that it will be affected by simple scope reconstruction (via a trace of type $\langle e t, t\rangle$ )? Another question relates to the issues discussed in section 5: Is there a way for the proposed alternative to account for the fact that under normal circumstances QR (as well as wh-movement) does not obviate Condition C effects?

${ }^{14}$ Romero (1996) presents additional arguments against the semantic account. In particular, she spells out the modifications in binding theory that the semantic approach would require and displays their stipulative nature. She also develops additional unwelcome results related to the interpretation of sluicing. 


\section{A-Reconstruction}

In this section I will show that the prediction in (10) holds for A-movement. The section has three parts. In section 2.1 I will focus on how many questions and elaborate on data from Heycock 1995. In section 2.2 I will explore standard constituent questions. The discussion will be based on data from Lebeaux 1990, which uses variable binding as a diagnostic for scope reconstruction. In section 2.3 I will continue the discussion of standard constituent questions. This time, indirect binding via adverbs of quantification will serve as the diagnostic for scope reconstruction.

Before I begin, a word of caution is in order. It is well known that certain cases of Amovement cannot bleed Condition C (Van Riemsdijk and Williams 1981, Freidin 1986, Lebeaux 1988). This inability holds independently of scope. Consider for example Lebeaux's pair in (11).

(11) a. [Which argument that $\mathrm{John}_{1}$ made] did he $\mathrm{e}_{1}$ believe $\mathrm{t}$ ?

b. ??/*[Which argument that $\mathrm{John}_{1}$ is a genius]

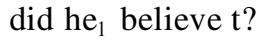

(11b) is unacceptable independently of scope reconstruction. In this section I will focus on cases such as (11a) in which A-movement does bleed Condition C. I will show that in these cases bleeding is incompatible with scope reconstruction. In other words, I will show that if an Aconstruction of the type in (9) is acceptable, it is disambiguated in favor of the non-scope-reconstruction interpretation.

\subsection{How Many Questions: An Elaboration on Heycock 1995}

Consider how many questions of the sort in (12). A plausible analysis of such questions assumes that the wh-phrase how many NP has two parts. One part consists of the wh-word how (which could be paraphrased as what n), and the other consists of the DP many NP (see Frampton 1991, Cresti 1995, Rullmann 1995). Roughly speaking, a how many question asks for an integer $n$, such that $n$ many individuals of a certain sort satisfy a certain property. This is illustrated in (13) and schematized in (14).

(12) [How many people $]_{1}$ did you meet $\mathrm{t}_{1}$ today?

(13) how $n$ many people $\lambda \mathrm{t}$ you met $\mathrm{t}$ today what is the number $n$, such that there are $n$ many people that you met today

(14) [how many NP $]_{1} \phi\left(\mathrm{t}_{1}\right)$ how $_{n} n$ many NP $\lambda \mathrm{t} \phi(\mathrm{t})^{15}$

\footnotetext{
${ }^{15}$ Obviously, stating the semantic type of $t$ would beg the question we are investigating. The claim that scope reconstruction is synctatic (for which I argue) amounts to the claim that the trace left by DPs always ranges over individuals (of type $e$ ) (see section 4).
} 
Consider now what happens when scope-sensitive elements intervene between the final landing site of the moved constituent and its trace position. In such a case the scope of the quantificational DP, many NP, can be construed either above or below this element (see, e.g., Longobardi 1987, Cresti 1995). This is demonstrated by the question in (15), which has the two readings shown in (15a) and (15b).

(15) How many people did Mary decide to hire?

a. many $>$ decide

what is the number $n$, such that

there are $n$ many people $x$, such that

Mary decided to hire $x$

b. decide $>$ many

what is the number $n$, such that

Mary decided to hire $n$ many people

The two readings of the question become visible once we consider situations in which they would demand different answers. ${ }^{16}$ Consider the following scenario:

(S1) After a day of interviews, Mary finds 7 people who really impress her, and she decides to hire them. None of the other people impress her. However, she knows that she needs more than 40 people for the job. After thinking about it for a while, she decides to hire 50 - the 7 that she likes and 43 others to be decided by a lottery.

It is clear that under (S1) there are two appropriate answers for (15). One answer is 7, which corresponds to interpretation (15a), and the other is 50, which corresponds to interpretation (15b). ${ }^{17}$

The ambiguity of (15) shows that the DP many NP can undergo scope reconstruction in how many questions. ${ }^{18}$ In this section I will present evidence from Heycock 1995 and expand on it to demonstrate that this reconstruction obeys the predictions in (10). This evidence will argue that scope reconstruction in how many questions should be dealt with by syntactic mechanisms.

${ }^{16}$ As Kai von Fintel (personal communication) points out, the two readings become even more visible once we insert the adverb already. This adverb tends to (though it does not have to) mark the scope of the quantificational DP. Thus, How many people did Mary already decide to hire? prefers the interpretation in (14a) and its natural answer given (S1) would be 7 . The reader who has problems with the scope judgments that follow might try to make use of the adverb.

${ }^{17}$ Noam Chomsky (personal communication) points out a possible caveat. Tense is not represented in (15). However, if we take tense into account, it is conceivable that the two interpretations would result from variability in the interpretation of tense (with no recourse to scope). More specifically, the two answers (given (S1)) could correspond to the two moments in time in which Mary made her decisions.

However, I think that this is not a real alternative. Take a sentence parallel to (15) that is not scopally ambiguous, such as Which people did Mary decide to hire? The proposal about tense would incorrectly predict a similar ambiguity in this sentence. I believe the prediction is incorrect because of a pragmatic tendency to give an answer that corresponds to Mary's final decision. Without any clear context, it makes no sense to give an answer that corresponds to tentative decisions that Mary made along the way.

Note that not much bears on this pragmatic explanation. The arguments in this section can be restated with the verb want, which can appear in the present tense (e.g., How many people does Mary want to hire?). Furthermore, the French examples in footnote 18 make it fairly clear that the ambiguity in (15) has to do with scope. (Thanks to Kai von Fintel for a helpful discussion of this issue.)

${ }^{18}$ As Heycock (1995) notes (attributing the observation to Carmen Dobrovie-Sorin), French has overt forms that disambiguate in favor of scope reconstruction. Although the (a) sentences in (i) and (ii) are equivalent to their English 
Consider the sentences in (16)-(18). ${ }^{19}$ In none of these sentences is Condition $\mathrm{C}$ an issue. However, the sentences differ minimally in a way that Heycock exploits to test the prediction in (10). ${ }^{20}$ The semantics of the embedded predicates in the (a) sentences forces, or at least highly prefers, scope reconstruction; by contrast, the (b) and (c) sentences are compatible with the nonscope-reconstruction reading. ${ }^{21}$ The (b) and (c) sentences are ambiguous along the lines of (15); the (a) sentences are limited to the interpretation in which the DP many NP has narrowest scope.

(16) a. [How many stories]

is Diana likely to invent $\mathrm{t}$ ?

(likely > many; *many > likely)

b. [How many stories]

is Diana likely to reinvent $\mathrm{t}$ ?

(likely > many; many > likely)

(17) a. [How many houses]

does John think you should build t?

$($ think $>$ many; *many $>$ think $)$

b. [How many houses]

does John think you should rebuild $\mathrm{t}$ ?

(think $>$ many; many $>$ think $)$

c. [How many houses]

does John think you should demolish $t$ ?

$($ think $>$ many; many $>$ think $)$

counterparts, the (b) and (c) sentences are unambiguous (with narrow scope for many). Thus, given (S1), the only answer for (ib) and (ic) is 50 (Marie Claude Boivin, personal communication).

(i) a. Combien de personnes Marie a-t-elle décidé d'engager?

how-many of people Marie has she decided to hire

b. ?Combien Marie a-t-elle décidé d'engager de personnes?

c. Combien Marie a-t-elle décidé d'en engager?

to of-them

(ii) a. Combien de livres Marie a-t-elle décidé d'acheter?

books to buy

b. ?Combien Marie a-t-elle décidé d'acheter de livres?

c. Combien Marie a-t-elle décidé d'en acheter?

${ }^{19}$ David Pesetsky (personal communication) suggested the use of the pair in (15) for the exposition of Heycock's results.

${ }^{20} \mathrm{I}$ am not sure whether what follows is entirely faithful to Heycock. The reason for this uncertainty is that Heycock alternates between an account of the ambiguity in (15) in terms of scope and an account in terms of a notion of referentiality (that will extend to an explanation of why VPs must reconstruct). Under the referentiality account that Heycock suggests, "nonreferential" phrases (whatever exactly this means; see Cinque 1990, Rizzi 1990, Frampton 1991) must show connectedness effects (i.e., binding theory reconstruction). The reason the (b) sentences exhibit connectedness effects is that the DP is interpreted nonreferentially. However, once we consider the structural configurations in (25), we will see that scope is not only the clearer notion, but also the empirically appropriate one.

${ }^{21}(17 \mathrm{~b})$ and (17c) are actually three-ways ambiguous. However, for the moment we can ignore the intermediate scope $($ think $>$ many $>$ should). 
(18) a. [How many papers that he $_{1}$ writes]

does $\mathrm{John}_{1}$ think $\mathrm{t}$ will be published? ${ }^{22}$

$($ think $>$ many; $*$ many $>$ think $)$

b. [How many papers that he $\mathrm{I}_{1}$ wrote]

does $\mathrm{John}_{1}$ think $\mathrm{t}$ will be published?

(think $>$ many; many $>$ think)

To see the contrast between the (a) and the (b) sentences, let us focus on (16a). Consider what an interpretation without scope reconstruction would be like. Such an interpretation would presuppose that there are certain stories such that Diana is likely to invent them. However, such a presupposition is virtually a contradiction. We think about the objects of invention as being created at the time of invention, and we therefore can't talk about these objects at earlier moments-hence the oddness of \#John will invent this story, \#Which of these stories is John likely to invent?

As Heycock notes, this difference allows us to test the prediction in (10). Consider (19)-(21). Only the (a) cases, in which scope reconstruction is forced, exhibit a Condition C effect. (Only the (a) cases are unacceptable. $)^{23}$

(19) a. *[How many stories about Diana's $s_{1}$ brother] is she $e_{1}$ likely to invent $\mathrm{t}$ ?

b. [How many stories about Diana's $s_{1}$ brother] is she likely to reinvent t $?^{24}$

(20) a. *[How many houses in John's $s_{1}$ city $]$ does he ${ }_{1}$ think you should build $t$ ?

b. [How many houses in John's $s_{1}$ city] does he ${ }_{1}$ think you should rebuild $t$ ?

${ }^{22}$ In this sentence the tense in the relative clause should be given a future interpretation. Wide scope for many would require John to have thoughts about specific papers. However, at the time of thinking there are no papers to have thoughts about; the papers will come to exist only in the future.

${ }^{23}$ In sections 5 and 6 I will follow Lebeaux (1988) in assuming that A-movement can bleed Condition C only if an adjunct is inserted after movement. The discussion in these sections will thus imply that the PPs in (19) and (20) are adjuncts. This implication, which might seem problematic at first sight, is argued for in Heycock 1995. See Schütze 1995 to appreciate the complexity of the complement/adjunct distinction (at least within the nominal domain).

A few speakers I have consulted find the (b) sentences in (19) and (20) slightly degraded. These speakers find the (a) sentences still worse. It seems plausible that these speakers prefer to analyze the PP as a complement. Still, they can marginally analyze it as an adjunct, which would allow Condition $\mathrm{C}$ to be obviated in (b) but not in (a).

${ }^{24}$ There is a potential problem with (19a) - namely, it might be illicit independently of reconstruction. To see this, consider the contrast in (i) and (ii). This contrast might be accounted for by postulating a PRO in the subject of the NPs in the (b) sentences along the lines suggested by Chomsky (1986b). (See also Higginbotham 1983 and Williams 1985, 1987.) If the correct account is along these lines, (19a) would have a Condition C violation (in the moved position) irrespective of whether or not reconstruction takes place. This confound is overcome in (20) and (22).

(i) a. Diana ${ }_{1}$ objected to many stories about her ${ }_{1}$.

b. * Diana $_{1}$ invented many $\left[\mathrm{PRO}_{1}\right.$ stories about her $\left.{ }_{1}\right]$.

(ii) a. Clifford ${ }_{1}$ expected many lies about him $_{1}$ to be effective.

b. ${ }^{*}$ Clifford $_{1}$ is planning to come up with many $\left[\mathrm{PRO}_{1}\right.$ lies about him 1 . 
c. [How many houses in John's $s_{1}$ city] does he ${ }_{1}$ think you should demolish $\mathrm{t}$ ?

(21) a. *[How many papers that John $_{1}$ writes] does he ${ }_{1}$ think $\mathrm{t}$ will be published?

b. [How many papers that $\mathrm{John}_{1}$ wrote] does he ${ }_{1}$ think $\mathrm{t}$ will be published?

We can also demonstrate that the unacceptability of the (a) cases is related to Condition $\mathrm{C}$ by comparing these sentences with $(22 \mathrm{a}-\mathrm{c})$. The latter sentences demonstrate that aside from Condition $\mathrm{C}$ there is nothing wrong with the conindexation in the former sentences.

(22) a. [How many stories about her ${ }_{1}$ brother] is Diana ${ }_{1}$ likely to invent $\mathrm{t}$ ?

b. [How many houses in his ${ }_{1}$ city] does $\mathrm{John}_{1}$ think you should build t?

c. [How many papers that he ${ }_{1}$ writes] does $\mathrm{John}_{1}$ think t will be published?

A paradigm similar to Heycock's can be constructed with sentences in which the definiteness effect holds. Consider the contrast between (23a) and (23b). In (23a) the definiteness effect forces scope reconstruction. (See Heim 1987, Frampton 1991.) Therefore, this question is restricted to the interpretation in which many people has narrow scope relative to the verb think. (23b), by contrast, is ambiguous. ${ }^{25}$

(23) a. [How many people]

does Diana think there are $\mathrm{t}$ at the party?

$($ think $>$ many; *many $>$ think $)$

b. [How many people]

does Diana think $\mathrm{t}$ are at the party?

$($ think $>$ many; many $>$ think)

Now consider the contrast in (24). (24a) is unacceptable because the obligatory scope reconstruction yields a Condition $C$ violation. (24b) and (24c) are minimally different. In (24b) scope reconstruction is not obligatory, and in $(24 \mathrm{c})$ it does not yield a Condition $\mathrm{C}$ effect. Therefore, the latter sentences are both acceptable.

(24) a. *[How many people from Diana' $s_{1}$ neighborhood] does she $_{1}$ think there are $\mathrm{t}$ at the party?

b. [How many people from Diana's ${ }_{1}$ neighborhood] does she $_{1}$ think $t$ are at the party?

c. [How many people from her ${ }_{1}$ neighborhood] does Diana ${ }_{1}$ think there are $\mathrm{t}$ at the party?

\footnotetext{
${ }^{25}$ To see the difference between the sentences, it might be helpful to construct scenarios parallel to (S1).
} 
(16)-(24) demonstrate that when scope reconstruction is forced, there are ramifications for Condition $\mathrm{C}$. This provides strong support for the assumption in (10) that scope reconstruction feeds Condition C. However, (10) makes further predictions for how many questions that we should be able to test. To see the range of these predictions, let us look again at (10) and the structural configuration, (9), to which it applies.

(9) $[\mathrm{Q} P \ldots \text { r-expression } 1 \ldots]_{2} \ldots \operatorname{pronoun}_{1} \ldots \mathrm{t}_{2}$

(10) Scope reconstruction feeds Condition $C$

Scope reconstruction should be impossible in the structural configuration in (9).

If (10) is right, it makes two predictions for the configuration (9). On the one hand, QP is obliged to take scope over all of the scope-bearing elements c-commanded by the pronoun. On the other hand, it is not obliged to take scope over the scope-bearing elements that c-command the pronoun. This is stated in (25).

(25) Predictions made by (10)

a. In (26) QP must take scope over the scope-bearing element $\mathrm{SB}^{1}$.

b. In (27) QP need not take scope over the scope-bearing element $\mathrm{SB}^{2} .^{26}$

(26) $\left[\mathrm{Q} P \ldots \text { r-expression }{ }_{1} \ldots\right]_{2} \ldots \operatorname{pronoun}_{1} \ldots \mathrm{SB}^{1} \ldots \mathrm{t}_{2}$

(27) $\left[\mathrm{Q} \text { P } \ldots \text { r-expression }{ }_{1} \ldots\right]_{2} \ldots \mathrm{SB}^{2} \ldots \operatorname{pronoun}_{1} \ldots \mathrm{t}_{2}$

(16)-(24) demonstrate that when independent factors force QP to take narrow scope with respect to $\mathrm{SB}^{1}$, the result is ill formed. I will now try to show that the predictions of (25) are also attested when these factors are not active.

Compare the pairs in (28) and (29).

(28) a. [How many slides of Jonathan's trip to Kamchatka]

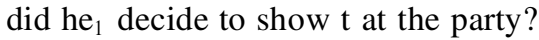

$($ many $>$ decide $; *$ decide $>$ many $)$

b. [How many slides of his ${ }_{1}$ trip to Kamchatka]

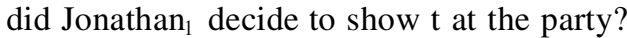

(many $>$ decide; decide $>$ many)

(29) a. [How many people from Diana's $s_{1}$ neighborhood]

does she $_{1}$ think $\mathrm{t}$ are at the party?

$($ many $>$ think; $*$ think $>$ many $)$

b. [How many people from her ${ }_{1}$ neighborhood]

does Diana $_{1}$ think $\mathrm{t}$ are at the party?

(many $>$ think; think $>$ many)

\footnotetext{
${ }^{26}$ The prediction in (25b) depends on the additional assumption that there is a position for reconstruction between $\mathrm{SB}^{2}$ and pronoun $_{1}$. This assumption is probably uncontroversial for the cases discussed in this section, since in all of these cases a CP node intervenes between the two positions. In section 2.2.2 I will give evidence for more reconstruction positions.
} 
The (a) sentences instantiate the structural configuration in (26), with the modal verbs decide and think standing for $\mathrm{SB}^{1}$. In these sentences many $N P$ must have wide scope over $\mathrm{SB}^{1}$, as predicted by (25). We can see this by comparing the possible answers to (a) and to (b) under the crucial scenarios.

The two readings of (28b) are paraphrased in (30). The difference between them is illustrated by the possible answers given the scenario (S2).

(30) a. many $>$ decide

what is the number $n$, such that

there are $n$ many slides of the trip to Kamchatka $x$, such that

Jonathan decided to show $x$ at the party

(answer given (S2): 52)

b. decide > many

what is the number $n$, such that

Jonathan decided to show $n$ many slides at the party

(answer given (S2): 100)

(S2) Jonathan wants to show slides from his trip to Kamchatka at a party. He tries to figure out how many slides he can show within an hour. After consulting with his roommate, Uli, he decides to show 100 slides (out of the 1,000 he has). Now it's time to choose the actual slides. After an hour of internal debate, he decides on 52 slides that he really likes and prepares them for display. The remaining 48 slides will be chosen at random at the time of the party.

By contrast, (28a) can have only the interpretation (30a); the only possible answer to this question given (S2) is 52 .

(29b) can have either the (think > many) interpretation, the interpretation of (24c), in which Diana doesn't need to have thoughts about any particular person, or the (many $>$ think) interpretation, in which it is presupposed that there are certain people who Diana thinks are at the party and the number of those is in question. Only the latter interpretation is available for (29a). (I invite the reader to construct the relevant scenarios.)

(28) and (29) show that QP in (26) cannot take scope under SB ${ }^{1}$. Now I would like to show that it can take scope under $\mathrm{SB}^{2}$ in (27). Furthermore, I would like to show that when $\mathrm{SB}^{2}$ and $\mathrm{SB}^{1}$ appear in the same construction (when (26) and (27) are combined), QP can have scope under the former but must take scope over the latter. ${ }^{27}$

Consider the contrast between (31a) and (31b). (31a) instantiates (26) and (31b) instantiates (27). (Decide instantiates both $\mathrm{SB}^{2}$ and $\mathrm{SB}^{1}$.) As (10) $(=(25))$ predicts, scope reconstruction is possible only in (31b). With the assistance of $(\mathrm{S} 2)$, we have already concluded that scope recon-

\footnotetext{
${ }^{27}$ The importance of this prediction lies in demonstrating that the phenomena should be accounted for by reference to scope and not to a notion such as referentiality, as is perhaps suggested by Heycock (see footnote 20). This is also the logic of Frampton's (1991) argument that scope (and not referentiality) is the relevant notion for the account of certain weak island phenomena.
} 
struction is impossible in (31a) $(=(28 a))$. (S3) is a minimal variation on (S2) (with the changes in italics), which demonstrates the contrast between the two questions. Given (S3), there are two possible answers to (31b), which correspond to the two possible scope relations.

(31) a. [How many slides of Jonathan's $s_{1}$ trip to Kamchatka] did he ${ }_{1}$ decide to show $\mathrm{t}$ at the party?

(many $>$ decide; $*$ decide $>$ many)

b. [How many slides of Jonathan's $s_{1}$ trip to Kamchatka] did Susi decide that he $\mathrm{f}_{1}$ would show $\mathrm{t}$ at the party?

(many $>$ decide; decide $>$ many)

(S3) Jonathan wants to show slides from his trip to Kamchatka at a party. Susi tries to figure out how many slides he can show within an hour. After consulting with their roommate, Uli, she decides that Jonathan will show 100 slides (out of the 1,000 he has). Now it's time to choose the actual slides. After an hour of internal debate, she decides on 52 slides that she really likes and prepares them for Jonathan's display. The remaining 48 slides will be chosen at random at the time of the party.

Now consider (S4), which starts with (S2) and then continues briefly.

(S4) Jonathan wants to show slides from his trip to Kamchatka at a party. He tries to figure out how many slides he can show within an hour. After consulting with his roommate, Uli, he decides to show 100 slides (out of the 1,000 he has). Now it's time to choose the actual slides. After an hour of internal debate, he decides on 52 slides that he really likes and prepares them for display. The remaining 48 slides will be chosen at random at the time of the party.

After all of this Jonathan tells Susi about his two decisions and wants to show her the 52 slides he's chosen. He shows her 30 of them, at which point she gets bored and says she wants to go to sleep. Jonathan tells her there are 22 more slides to see, and she says she will see them during the party.

The relevant facts are these:

(32) a. Susi knows

i. that Jonathan decided to show 100 slides at the party.

ii. that there are 52 slides such that Jonathan decided to show them.

b. There are 30 slides such that Susi knows that Jonathan decided to show them.

Given (S4), question (33) is three-ways ambiguous; that is, it has three possible answers.

(33) How many slides did Susi know that Jonathan decided to show at the party?
a. 30 (many $>$ know $>$ decide)
b. 52 (know $>$ many $>$ decide)
c. 100 (know $>$ decide $>$ many)

Now consider the contrast in (34). (34b) is three-ways ambiguous, just as (33) is. By contrast, 
(34a) is only two-ways ambiguous. In (34a) many can take scope either above or below know $\left(=\mathrm{SB}^{2}\right)$. However, the scope of many relative to decide $\left(=\mathrm{SB}^{1}\right)$ is fixed (many $>$ decide); given (S4), the only possible answers to (34a) are 30 and 52. This is exactly as (25) predicts.

(34) a. [How many slides of Jonathan's ${ }_{1}$ trip to Kamchatka]

did Susi know that he ${ }_{1}$ decided to show $t$ at the party?

b. [How many slides of his s $_{1}$ trip to Kamchatka]

did Susi know that Jonathan $_{1}$ decided to show $\mathrm{t}$ at the party?

We have thus seen that the predictions of syntactic reconstruction hold for how many questions. Scope reconstruction has consequences for Condition $\mathrm{C}$ in exactly the manner predicted by $(10){ }^{28}$

\subsection{Variable Binding: An Elaboration on Lebeaux 1990}

Consider the option for variable binding in the constituent questions in (35). As is well known, this option is available only if the trace of the wh-element is c-commanded by the binder of the variable. This is illustrated by the unacceptability of the questions in (36).

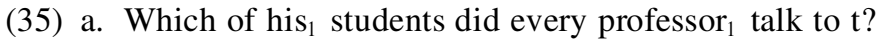

b. Which student of his $\mathrm{s}_{1}$ did no professor $_{1}$ talk to $\mathrm{t}$ ?

c. Which student of his $s_{1}$ did you think every professor ${ }_{1}$ talked to $t$ ?

d. Which of his ${ }_{1}$ students did you think no professor ${ }_{1}$ talked to $t$ ?

(36) a. *Which of his ${ }_{1}$ students t talked to every professor ${ }_{1}$ ?

b. *Which student of his $_{1} \mathrm{t}$ talked to no professor ${ }_{1}$ ?

c. *Which student of his ${ }_{1}$ did you think t talked to every professor ${ }_{1}$ ?

d. *Which of his ${ }_{1}$ students did you think t talked to no professor ${ }_{1}$ ?

2.2.1 The Correlation with Condition $C$ As with previous cases, there are two possible approaches. Under one approach, due to Engdahl (1980), part of the wh-element is in the trace position, and this syntactic configuration allows for variable binding (syntactic reconstruction). Under another approach, due to Engdahl (1986), various semantic mechanisms are postulated to yield the semantic effects of variable binding without actual reconstruction (semantic reconstruction).

These two approaches can be distinguished by the prediction (of the syntactic approach) that scope reconstruction feeds Condition C. If the cases in (35) require reconstruction in the syntax, there should be consequences for Condition $\mathrm{C}$. If, however, there are semantic mechanisms that allow for the interpretations in (35) without actual reconstruction, there should be no such consequences. Lebeaux's (1990) pair in (37) demonstrates that the prediction of the syntactic approach is correct.

${ }^{28}$ Although the questions in (34) seem extremely complex, speakers' judgments converge. The scenario in (S4) was read to 5 speakers and they all agreed that 100 is an appropriate answer only to (34b) whereas 30 and 52 are possible answers to both (34a) and (34b). 
(37) a. [Which (of the) paper(s) that he 1 gave to Ms. Brown $\left.{ }_{2}\right]$ did every student $t_{1}$ hope $\mathrm{t}^{\prime}$ that she $_{2}$ will read $\mathrm{t}$ ?

b. *[Which (of the) paper(s) that he ${ }_{1}$ gave to Ms. Brown 2$]$ did she $e_{2}$ hope $\mathrm{t}^{\prime}$ that every student $t_{1}$ will revise $\mathrm{t}$ ?

In both sentences in (37) part of the wh-phrase must undergo scope reconstruction to a position c-commanded by the QP every student (the antecedent of the bound variable he). In (37b) every student is c-commanded by the pronoun she, which is in turn coindexed with Ms. Brown. Therefore, in (37b) scope reconstruction yields a Condition C effect. In (37a) every student is not c-commanded by the pronoun she, and therefore there is a position for reconstruction (perhaps the position of $t^{\prime}$ ) that is within the scope of the antecedent of $h e$, but not low enough to yield a Condition $\mathrm{C}$ effect. The contrast is thus explained under the assumption that scope reconstruction feeds Condition C.

In fact, once we understand the logic of (37), we see that the conclusion regarding the relation between scope reconstruction and Condition $\mathrm{C}$ can be demonstrated with additional examples, some of which come close to being real minimal pairs. The logic is basically the logic of (9) and (10), repeated here.

(9) $\left[\mathrm{QP} \ldots . \mathrm{r} \text {-expression }{ }_{1} \ldots\right]_{2} \ldots \operatorname{pronoun}_{1} \ldots \mathrm{t}_{2}$

(10) Scope reconstruction feeds Condition C

Scope reconstruction should be impossible in the structural configuration in (9).

(37b) is illicit because it is an instance of (9) that requires scope reconstruction to a position below the pronoun. We know that scope reconstruction is necessary because there is a quantifier below the pronoun that must have a variable dominated by QP within its scope. In (37a) the quantifier is above the pronoun and hence scope reconstruction need not bring about a Condition $\mathrm{C}$ effect.

The predictions of (10) for the constructions that Lebeaux investigated can be summarized by the schemas in (38), in which the underlined blanks represent potential reconstruction positions. Instances of (38a) should be acceptable because they do not require scope reconstruction of the $w h$-element to a position below pronoun ${ }_{2}$; there could be reconstruction to a position between the pronoun and QP in which the variable is bound and Condition C is nevertheless satisfied. ${ }^{29}$ Instances of (38b) should be unacceptable because they require scope reconstruction of the $w h$ element to a position below $\mathrm{QP}_{1}$, which is in turn below pronoun $n_{2}$; any form of reconstruction that would allow the variable to be bound will necessarily bring about a Condition $\mathrm{C}$ effect.

(38) a. $\left[{\text { which. } \ldots \operatorname{pronoun}_{1} \ldots \text { r-expression }}_{2}\right] \ldots \mathrm{QP}_{1} \ldots \ldots \ldots \operatorname{pronoun}_{2} \ldots * \ldots$ b. $\left[\right.$ which. . pronoun $_{1} \ldots$ r-expression $\left.{ }_{2}\right] \ldots$ pronoun $_{2} \ldots * \ldots \mathrm{QP}_{1} \ldots *+\ldots$

The important difference between the schemas in (38) is that only in (38b) does the kind of scope reconstruction that is needed bring about a Condition $\mathrm{C}$ effect. However, there is an addi-

\footnotetext{
${ }^{29}$ Note that the prediction holds only under the assumption that there is a reconstruction position between $\mathrm{QP}_{1}$ and pronoun $_{2}$. See section 2.2.2.
} 
tional difference between the structures. In (38b) a more radical kind of scope reconstruction is needed. We should therefore add a control to the paradigm. We need to compare (38b) with (39), which needs the same kind of scope reconstruction but is irrelevant to Condition C. ${ }^{30}$

(39) $\left[{\left.\text { which. . } \text { pronoun }_{1} \ldots \text { pronoun }_{2}\right] \ldots \text { rexpression }}_{2}\right] \ldots * * \ldots \mathrm{QP}_{1} \ldots \ldots \ldots$

Even with the control, the predictions of syntactic reconstruction are borne out. This is demonstrated in (40)-(42). The (a) and (b) examples instantiate (38a) and (38b), respectively; the (c) examples instantiate the control in (39). The results show that scope reconstruction, which is diagnosed by variable binding, feeds Condition $\mathrm{C}$.

(40) a. [Which of the books that he $\mathrm{e}_{1}$ asked Ms. Brown ${ }_{2}$ for] did every student 1 get from her ${ }_{2} *$ ?

b. *[Which of the books that he $e_{1}$ asked Ms. Brown ${ }_{2}$ for] did she $_{2} *$ give every student $t_{1} *$ ?

c. [Which of the books that he ${ }_{1}$ asked her ${ }_{2}$ for] did Ms. Brown 2 * give every student $t_{1} \_$?

(41) a. [Which (of the) paper(s) that he $e_{1}$ wrote for Ms. Brown $n_{2}$ ] did every student $t_{1} \ldots$ get her ${ }_{2} *$ to grade?

b. *[Which (of the) paper(s) that he $e_{1}$ wrote for Ms. Brown $\left.n_{2}\right]$ did she $_{2} *$ get every student $t_{1} *$ to revise?

c. [Which (of the) paper(s) that he ${ }_{1}$ wrote for her ${ }_{2}$ ] did Ms. Brown 2 * get every student $t_{1}$ to revise?

(42) a. [Which (of the) paper(s) that he ${ }_{1}$ gave Ms. Brown ${ }_{2}$ ] did every student ask her $_{2}$ to read * carefully?

b. *[Which (of the) paper(s) that he $\mathrm{e}_{1}$ gave Ms. Brown $\left.{ }_{2}\right]$ did she $_{2} *$ ask every student 1 to revise $*$ ?

c. [Which (of the) paper(s) that he $\mathrm{e}_{1}$ gave her $\mathrm{r}_{2}$ ] did Ms. Brown 2 * ask every student to revise

2.2.2 The Multitude of Intermediate Landing Sites We have just used the schemas in (38) (repeated here) to argue that scope reconstruction feeds Condition C.

(38) a. [which....pronoun p $_{1} \ldots$ r-expression 2$] \ldots \mathrm{QP}_{1} \ldots$ $\ldots \operatorname{pronoun}_{2} \ldots *$ * $\ldots$ b. *[which. . pronoun 1 . .r-expression $\left.{ }_{2}\right] \ldots$ pronoun $_{2} \ldots * \ldots . \mathrm{QP}_{1} \ldots * * \ldots$

${ }^{30}$ From the tests I conducted, it is apparently very important to put pronoun 2 and $\mathrm{QP}_{1}$ in (38) as close as possible to each other, so as to minimize the differences between the sentences with respect to the distance between the bound variable and its antecedent. It seems that when the distance is very great, (38b) and (39) involve a terrible parsing load. This parsing load makes the judgment very difficult, and it is hard to detect the effects of Condition C. Thus, although (i) seems better than (37b), it seems worse than (37a).

(i) ??[Which (of the) paper(s) that he gave to her $\left._{2}\right]$ did Ms. Brown $n_{2}$ hope $t^{\prime}$ that every student $t_{1}$ will revise $t$ ? 
A crucial assumption was that (38a) contains an intermediate position for scope reconstruction between $\mathrm{QP}_{1}$ and pronoun $_{2}$. Now I would like to point out that one could conduct an investigation in the other direction. In particular (assuming that the arguments in this article are compelling), one could attempt to take for granted the assumption that scope reconstruction feeds Condition $\mathrm{C}$ and use the schemas in (38) to test what type of intermediate scope reconstruction positions are available. Such an investigation is beyond the scope of this article. Nevertheless, I would like to point out one conclusion that would necessarily follow. This conclusion, although irrelevant at this point in the discussion, will play a crucial role in later sections. (See in particular section 5.1.)

Consider the acceptability of the (a) sentences in (40)-(42). Under the assumption that scope reconstruction feeds Condition $\mathrm{C}$, the grammaticality of these sentences forces the conclusion that there is a reconstruction position between the subject and the object. To illustrate this, I repeat the examples with the crucial reconstruction position in brackets. ${ }^{31}$

(40) a. [Which of the books that he ${ }_{1}$ asked Ms. Brown 2 for] did every student ${ }_{1}[\ldots]$ get from her h_ $_{2}$ ?

(41) a. [Which (of the) paper(s) that he ${ }_{1}$ wrote for Ms. Brown ${ }_{2}$ ] did every student ${ }_{1}[\ldots]$ get her L_ $_{2}^{*}$ to grade?

(42) a. [Which (of the) paper(s) that he ${ }_{1}$ gave Ms. Brown ${ }_{2}$ ] did every student $t_{1}[\ldots]$ ask her ${ }_{2}$ to read _ $*$ carefully?

If we believe that reconstruction should follow from the copy theory of movement, we have a direct argument that there must be an intermediate landing site for A-movement between the subject and the object. For presentational purposes I will assume that the landing site is adjunction to VP, along the lines proposed by Chomsky (1986a). ${ }^{32}$

\subsection{Unselective Binding}

In section 2.2 I used variable binding as a diagnostic for scope reconstruction. I showed that when part of a moved phrase in a wh-question needs to be reconstructed for variable binding, there are consequences for Condition C. In this section I will show that the same holds for unselective binding. ${ }^{33}$

${ }^{31}$ One might suggest that there are fewer reconstruction positions and that QR over higher reconstruction positions (than the bracketed ones in the (a) sentences of (40)-(42)) allows for variable binding. However, binding from QRed positions should be ruled out by WCO. Furthermore, without WCO it is hard to see how the (b) sentences could be ruled out.

${ }^{32}$ Nissenbaum (forthcoming) provides independent evidence for VP-adjoined traces in A-movement. From a rudimentary investigation of constructions that fall under the schema in (38), it seems to me that a stronger conclusion will follow. In particular, I believe one can construct an argument for the existence of intermediate landing sites in every maximal projection.

${ }^{33}$ The idea of using unselective binding as a diagnostic for scope reconstruction was inspired by chapter 3 of Chierchia 1995a (although the construction I test and the conclusion I draw are very different). Thanks to Orin Percus for help in constructing the experimental paradigms. 
Consider the sentences in (43) and (44). (43) has an interpretation in which the indefinite is bound by the unselective binder; (44) does not. To see what is meant, let us focus on the (a) sentences. (43a) has an interpretation under which the indefinite an artist is bound by the unselective binder, usually. Under this interpretation the question can be paraphrased as something like which are the types of friends $s_{x}$ such that you said that for most artists $s_{y}$-type friends of $y$ are available. (44a) does not have a comparable interpretation.

(43) a. [Which friends of an artist ${ }_{1}$ ] did you say $t$ are usually $y_{1}$ available?

b. [Which of the people that an artist meets] $_{1}$ did you say $t$ never impress $_{\text {him }}$ ?

(44) a. *[Which friends of an artist $\left.{ }_{1}\right]$

t said that they are usually available? $^{2}$

b. *[Which of the people that an artist meets] $^{2}$

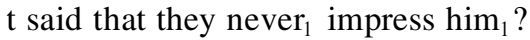

The contrast follows straightforwardly from the assumption that an indefinite that is bound by an adverb of quantification must be within its scope at LF. ${ }^{34}$ In (43) the trace of the wh-phrase is within the scope of the adverb, and the necessary configuration can be achieved via scope reconstruction. In (44) the trace of the wh-phrase is outside the scope of the adverb, and the necessary configuration for binding cannot be achieved.

The sentences in (43) and (44) contrast with respect to the availability of the intended interpretation. We can make the judgment sharper by considering constructions in which the intended interpretation is the only one available. Specifically, we will consider constructions in which independent factors require that the indefinite be bound by the adverb of quantification. In such constructions the counterparts of (43a) and (43b) will be ungrammatical independently of interpretation.

Kratzer (1995) observes that in individual-level predicates, an adverb of quantification must cooccur with an indefinite. This observation is demonstrated by the contrast in (45). (45a) is ungrammatical because there is no variable that is supplied to the adverb of quantification (vacuous quantification). (45b) is grammatical because the indefinite supplies the variable.

(45) a. *John usually ${ }_{1}$ knows French.

b. A Moroccan usually $_{1}$ knows French.

Now consider the grammaticality contrast among the questions in (46). In (46a) and (46b) the indefinite can get into the scope of the adverb via scope reconstruction. In (46c) this is impossible since the trace of the $w h$-element is outside the scope of the adverb. (46c) is ungrammatical because binding of the indefinite is both impossible (given the position of the trace) and required (given the ban on vacuous quantification).

\footnotetext{
${ }^{34}$ Many different theories have been proposed for the binding of indefinites by adverbs of quantification. All these theories, I believe, share the assumption that the indefinite must be within the scope of the adverb.
} 
(46) a. [Which residents of a French town ${ }_{1}$ ]

t usually know English?

b. [Which residents of a French town $n_{1}$ ]

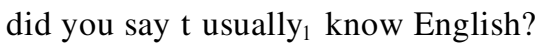

c. *[Which residents of a French town $\left.n_{1}\right]$

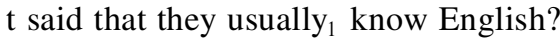

With this much in hand, we have an additional test for the prediction that scope reconstruction feeds Condition C. In this test the binding of an indefinite by an adverb of quantification will serve as a diagnostic for scope reconstruction and the consequences for Condition $\mathrm{C}$ will be examined. The examination will be based on the assumption that, as far as Condition $\mathrm{C}$ is concerned, an indefinite acts like an r-expression even when it is bound by an adverb of quantification. (See Lasnik 1976 and Chierchia 1995b.) This assumption is based on contrasts such as those in (47).

(47) a. $* \mathrm{He}_{1}$ usually $y_{1}$ thinks that an artist $\mathrm{t}_{1}$ is creative.

b. An artist usually $_{1}$ thinks that he ${ }_{1}$ 's creative.

c. His H $_{1}$ parents usually think that an artist $t_{1}$ is creative.

d. The parents of an artist $t_{1}$ usually think that he' $s_{1}$ creative.

Although unselective binding seems a little more complicated than the cases we have looked at before, the logic is identical. Just as before, we will look at constructions such as those in (9) and test the prediction in (10). The r-expression in the test will be an indefinite, and the diagnostic for scope reconstruction will be the binding of this indefinite by an adverb of quantification.

(9) $\left[Q \mathrm{Q} \ldots \text { r-expression }{ }_{1} \ldots\right]_{2} \ldots$ pronoun $_{1} \ldots \mathrm{t}_{2}$

(10) Scope reconstruction feeds Condition C

Scope reconstruction should be impossible in the structural configuration in (9).

It seems that the prediction in (10) is correct. To see this, consider first the contrast in (48). In (48a) the principle that bans vacuous quantification forces scope reconstruction. Scope reconstruction in turn yields a Condition $\mathrm{C}$ effect, and the sentence is ruled out. In (48b) and (48c), by contrast, scope reconstruction does not yield a Condition $C$ violation. In (48d) the individual-level predicate is replaced by a stage-level predicate. For this reason, scope reconstruction is not forced and Condition $\mathrm{C}$ is not affected.

(48) a. *[Which languages spoken in the country a linguist $t_{1}$ comes from] does he usually $_{1}$ know $\mathrm{t}$ ?

b. [Which languages spoken in the country he $e_{1}$ comes from] does a linguist ${ }_{1}$ usually know $\mathrm{t}$ ?

c. [Which languages spoken in the country a linguist $t_{1}$ comes from] do his $_{1}$ students usually know ?

d. [Which languages spoken in the country a (certain) linguist comes from] $_{1}$

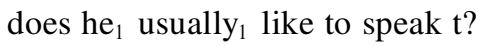


Next consider the contrast in (49). In (49a) the position of the adverb of quantification forces scope reconstruction to a position c-commanded by the pronoun. In (49b), by contrast, there is a position, $t^{\prime}$, that satisfies the requirements of the adverb and yet does not yield a Condition $\mathrm{C}$ effect. In (49c) and (49d) scope reconstruction is forced to the position of $t$, but the result does not violate Condition $\mathrm{C}$. (This indicates that the problem with (49a) is related to Condition $\mathrm{C}$ and is not an independent problem with scope reconstruction.) ${ }^{35}$

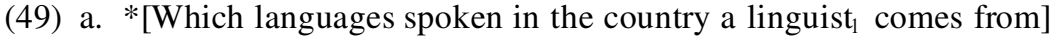
did you say that he usually $_{1}$ knows $t$ ?

b. [Which languages spoken in the country a linguist comes from] $_{1}$ com $^{-}$ do you usually $_{1}$ say $\mathrm{t}^{\prime}$ that he $\mathrm{e}_{1}$ knows $\mathrm{t}$ ?

c. [Which languages spoken in the country that he ${ }_{1}$ comes from] did you say that a linguist usually $_{1}$ knows $\mathrm{t}$ ?

d. [Which languages spoken in the country a linguist comes from] $_{1}$

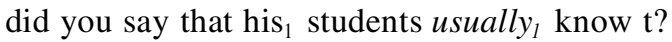

(48) and (49) thus provide an additional argument that scope reconstruction feeds Condition C.

\section{A-Reconstruction}

Having shown that $\bar{A}$-reconstruction feeds Condition $\mathrm{C}$ and thus obeys the predictions of the syntactic account, I now argue that the same is true of A-reconstruction. Unfortunately, the data on A-reconstruction are not as clear as the data on A-reconstruction. Nevertheless, I think they go in the right direction (see footnote 36).

Let us look at cases of A-reconstruction of the sort introduced in section 1. Consider the ambiguous sentences in (50), and focus on (50a). Under one of its interpretations, the sentence is true only if there is a particular first-year student who David believes is at the party $(\exists>$ seem). Under the other interpretation, there doesn't need to be such a student. The sentence is true if David is at the party and happens to hear a conversation regarding the topics discussed in the intro class, and if this conversation prompts him to conclude that there must be at least one first-year student in the room $($ seem $>\exists)$.

(50) a. [A first-year student] seems to David t to be at the party.

b. [Someone from New York] is very likely t to win the lottery.

As I argued in section 1, this ambiguity should be accounted for by the availability of scope reconstruction to the position of the trace. If scope reconstruction does not occur, the sentence has the $(\exists>$ seem $)$ interpretation. If scope reconstruction does occur, it has the (seem $>\exists$ ) interpretation.

Now we can test whether scope reconstruction feeds Condition C in the case of A-movement. It seems that it does. Consider the sentences in (51) and (52). It seems that the (a) sentences are

\footnotetext{
${ }^{35} \mathrm{I}$ am ignoring various issues regarding the necessary focus structure of the constituent questions. My hope is that the resolution of these issues will not affect the results reported here.
} 
disambiguated in favor of the $(\exists>$ seem) interpretation. To see this, focus on (51a). This sentence is true only if David has a thought about a particular student of his. It would not be true in the situation I used for illustrating the $($ seem $>\exists$ ) interpretation of $(50 \mathrm{a})$. This follows straightforwardly from the assumption that scope reconstruction feeds Condition $\mathrm{C}$. $^{36}$

(51) a. [A student of David's $s_{1}$ seems to him t $_{1}$ to be at the party.

$(\exists>$ seem; $*$ seem $>\exists)$

b. [A student of his 1 ] seems to David to be at the party.

$$
(\exists>\text { seem; seem }>\exists)
$$

(52) a. [Someone from David's $s_{1}$ city] seems to $\operatorname{him}_{1}$ t to be likely to win the lottery.

$$
(\exists>\text { seem; } * \text { seem }>\exists)
$$

b. [Someone from his $s_{1}$ city] seems to David t $_{1}$ to be likely to win the lottery.

$(\exists>$ seem; seem $>\exists)$

\section{Ramifications for the Interpretation of Chains}

The fact that scope reconstruction feeds Condition $\mathrm{C}$, which follows straightforwardly from syntactic accounts of scope reconstruction, cannot be explained by the semantic account and thus provides an argument in favor of syntactic accounts. This argument has certain consequences for semantics. In particular, it implies that the procedures that were suggested for semantic reconstruction must be restricted.

To appreciate this implication, let us look again at the chain in (2a), repeated here. As mentioned in section 1.2, plausible principles for the interpretation of chains (Heim and Kratzer, forthcoming) yield the interpretations in (53).

(2) a. [Someone from New York] is very likely [t to win the lottery].

(53) a. [someone from New York] $\lambda x$ (is very likely [ $x$ to win the lottery])

b. [someone from New York] $\lambda \mathrm{Q}$ (is very likely [Q to win the lottery])

(53b) yields the semantic effects of scope reconstruction without actual reconstruction. If this semantic interpretation is possible, we incorrectly predict no correlation between reconstruction and Condition $\mathrm{C}$. We therefore need to rule out (53b). We need a principle from which it would follow that a trace in a $\theta$-position is interpreted as a variable that ranges over individuals (type

${ }^{36}$ So far (51) and (52) have been tested with 12 speakers. Eight of the speakers got the contrast between the (a) and the (b) sentences that I report, and some of them thought that the judgments were strong. Four speakers got no contrast. Data similar to those presented here were reported independently in Romero 1996 and Sportiche 1996. I assume that this lends support to the reality of the effect. I also obtained more or less the same results using Lebeaux's (1994) observation that inverse scope in constructions such as (i) and (ii) depends on scope reconstruction (see section 1). The split was also the same: a little more than half the speakers tested got inverse scope only in (i).

(i) a. At least one of his ${ }_{1}$ soldiers is expected by Napoleon ${ }_{1}$ to die in every battle.

b. One of his ${ }_{1}$ soldiers is expected by Napoleon $_{1}$ to die in every battle.

(ii) a. At least one of Napoleon's ${ }_{1}$ soldiers is expected by him $_{1}$ to die in every battle.

b. One of Napoleon's $s_{1}$ soldiers is expected by him h $_{1}$ to die in every battle. 
e). Space limitations do not allow me to discuss various possibilities. (See Beck 1996 for a promising proposal.) Nevertheless, I think it is important to stress the obvious consequences for semantics: if type-shifting operations are allowed in the semantic component at all, they must be restricted; something must be added in order to ensure that the scope of moved constituents will be reflected in the syntax. ${ }^{37}$

\section{Where Does Binding Theory Apply?}

The correlation between scope reconstruction and Condition $\mathrm{C}$ argues in favor of two conclusions. First, it argues that scope reconstruction should be represented structurally (i.e., that there is syntactic reconstruction). Second, it argues that binding theory should be sensitive to the LF position of quantificational expressions; that is, it argues that binding theory applies at LF. However, it is widely believed that covert QR does not affect Condition C (Chomsky 1981). This can be taken as an argument that Condition C applies at S-Structure as well as at LF (Lebeaux 1994).

What I would like to claim now is that binding theory, or at least Condition C, applies only at LF. My argument will have two steps familiar from Chomsky 1993. The first step-which was actually already taken by Chomsky and in which I will basically follow his assumptions (though perhaps not the mode of his implementation) — argues that, contrary to initial appearances, there is a coherent story to be told in which binding theory applies only at LF. The second step argues that the alternative, in which binding theory (and specifically Condition C) also applies at other levels of representation, is empirically inferior. This second step is based on Fox 1995a. ${ }^{38}$

\subsection{The First Step of the Argument (Chomsky 1993)}

Let us begin by reviewing the evidence that is taken to show that Condition C applies at SStructure. Consider the contrast between (54) and (55). Under certain assumptions about the nature of covert QR (Chomsky 1977, May 1977, 1985), the LF structures of the sentences in (54) are those in (56). With respect to Condition $\mathrm{C}$, these structures are identical to the S-Structure representations in (55). If Condition $\mathrm{C}$ applied only at LF, there would be no obvious way of accounting for the contrast. If it applied at S-Structure as well, the contrast would follow straightforwardly. ${ }^{39}$

${ }^{37}$ At the moment I see two possibilities, both of which seem fairly natural: (a) traces, like pronouns, are always interpreted as variables that range over individuals (type $e$ ); (b) the semantic type of a trace is determined to be the lowest type compatible with the syntactic environment (as suggested in Beck 1996).

${ }^{38}$ Chomsky (1993) also presents the second step of the argument. However, his argument is based on Condition A and is unrelated to scope.

${ }^{39}$ Given the proposal made in Fox 1995b, the structures in (54) involve very short QR, or perhaps no QR at all. Under this proposal, the LF structures of (54) are very different from (56), and it is thus far from obvious that they pose a problem for the assumption that Condition C applies only at LF. However, it turns out that the argument based on (54) carries over to structures for which this objection does not hold.

(i) a. */??A different girl bought him ${ }_{1}$ every picture that $\mathrm{John}_{1}$ liked.

b. *A different girl wanted him him $_{1}$ to buy every picture that $\mathrm{John}_{1}$ liked.

(ii) a. A different girl bought $\mathrm{John}_{1}$ every picture that he ${ }_{1}$ liked.

b. A different girl wanted $\mathrm{John}_{1}$ to buy every picture that he $\mathrm{l}_{1}$ liked. 
(54) a. */??You bought him 1 every picture that $\mathrm{John}_{1}$ liked.

b. ${ }^{*} \mathrm{He}_{1}$ bought you every picture that $\mathrm{John}_{1}$ liked.

(55) a. [[Which picture that $\mathrm{John}_{1}$ liked] [did you buy him 1 t]]?

b. [[Which picture that $\mathrm{John}_{1}$ liked] [did he 1 buy you t]]?

(56) a. [[Every picture that $\mathrm{John}_{1}$ liked] [I bought him 1 t]].

b. [[Every picture that $\mathrm{John}_{1}$ liked] [he $\mathrm{H}_{1}$ bought you t]].

5.1.1 Chomsky's Proposal Chomsky (1993), however, provides a way of accounting for the contrast without the assumption that Condition $\mathrm{C}$ applies at S-Structure. In particular, he suggests that A-movement always leaves a copy and that this copy (under certain circumstances) yields a Condition $\mathrm{C}$ effect, even if Condition $\mathrm{C}$ applies only to the output of movement. In (54) the true output of QR is quite different from (56). Specifically, it still has a copy of the moved constituent at the position of the trace, and it is the r-expression within this copy that yields the violation of Condition C. In (55), Chomsky claims (following Lebeaux 1988), A-movement applies prior to the insertion of the relative clause that contains the r-expression. Therefore, in (55) the copy of the moved constituent does not yield a Condition $\mathrm{C}$ effect. The difference between overt and covert movement under this proposal is related not to their respective ordering relative to binding theory but to their respective ordering relative to lexical insertion. ${ }^{40}$ Covert movement is never followed by lexical insertion and therefore never appears to circumvent a Condition $\mathrm{C}$ violation.

As it turns out, certain cases of overt movement are similar to the cases of covert movement in that they are unable to circumvent a Condition $C$ violation. These cases are demonstrated by Lebeaux's (1988) contrast between (11a) and (11b), repeated here.

(11) a.

[Which argument that John made]

did he believe t?

b. ??/*[Which argument that John is a genius]

did he believe t?

Chomsky accounts for this contrast on the basis of a distinction between the timing of adjunct insertion and the timing of complement insertion, whch he also borrows from Lebeaux. According to this distinction, complements, in contrast to adjuncts, must be inserted prior to movement (in accordance with the extension/projection principle). From this it follows that complements, such as the italicized phrase in (11b), in contrast to adjuncts, such as the relative clause in (11a), cannot obviate Condition $\mathrm{C}$ via overt A-movement. ${ }^{41}$

\footnotetext{
${ }^{40}$ Note that the claim that overt and covert movement differ in their ordering relative to lexical insertion is strongly motivated on independent grounds. There is strong independent motivation for the claim that lexical insertion cannot follow covert operations (at least not without severe constraints). If this claim were false, it is hard to imagine how any correspondence between meaning and sound could be accounted for.

${ }^{41}$ One might wonder whether the possibility of inserting adjuncts at various points in the derivation is consistent with the observation in section 2 that A-reconstruction feeds Condition C. In section 6 I will show that it is consistent. The basic idea is that scope reconstruction is the result of interpreting a large part of the copy at the base position. I will show that such an interpretation is available only if the adjunct is inserted at the base position; the option of late insertion necessarily yields the nonreconstructed interpretation.
} 
It turns out that overt $\bar{A}$-movement of certain phrases (phrases that contain complements and no adjuncts) is identical to covert movement with respect to Condition $\mathrm{C}$. This weakens the argument from (54) and (55) that Condition $\mathrm{C}$ makes an overt/covert distinction. Nevertheless, this provides only the first stage of the argument that Condition C applies only at LF. It is still possible to account for all the data under the assumption that Condition $\mathrm{C}$ applies both at $\mathrm{S}$ Structure and at LF (see Lebeaux 1988, 1994). In the remainder of this section, I would like to present the argument from Fox 1995a that Condition C must apply only at LF. The argument is based on an observation by Fiengo and May (1994) that certain cases of covert movement do in fact obviate Condition $\mathrm{C}$. This observation cannot be accounted for under the assumption that Condition $\mathrm{C}$ applies at S-Structure.

5.1.2 The Interpretation of A-Chains: A Slight Modification The discussion thus far has not spelled out the nature of the structures that are interpreted. As noted by Chomsky (1993), interpreting an operator-variable construction probably requires some alterations of the copies created by movement. In particular, Chomsky suggests that the output of movement in structures such as (57), which is fully represented in (58), undergoes a later process that forms one of the structures in (59).

(57) Which book did Mary read t?

(58) which book did Mary read which book

(59) a. which book $_{x}$ did Mary read $x$

b. which $_{x}$ did Mary read book $x^{42}$

Further, he stipulates that the structure in (59b) is preferred to the structure in (59a), thus accounting for the Condition $\mathrm{C}$ violation in (11b). I will basically follow this assumption, but will modify the implementation slightly. This modification will make the interpretation of the QRed structures more straightforward and will perhaps allow the stipulation to follow from general principles of economy. Under the modification, the two structures are those in (60).

(60) a. which book did Mary read $x$ (ruled out by economy)

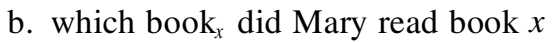

(60a) is interpreted standardly. For (60b), something novel needs to be proposed. Various possibilities come to mind. For concreteness, I follow a suggestion made by Sauerland (in progress). (See also Rullmann and Beck 1998.) According to this possibility, book $x$ is interpreted as a definite description, the book identical to $x$, yielding an interpretation paraphrasable as which is the book, $x$, such that Mary read the book identical to $x .^{43}$ The specifics of this proposal are not crucial

${ }^{42}$ It is conceivable that these structures should be interpreted via quantification over choice functions (Reinhart 1995, Kratzer 1998, Winter 1995, Engdahl 1980:131-141). However, as pointed out by Irene Heim, Uli Sauerland, and Yoad Winter (personal communications), it is not clear how such an analysis would extend to proportional quantifiers (e.g., most, almost, every). This is one of the motivations for the modification that follows.

${ }^{43}$ Rullmann and Beck consider this possibility as a method for interpreting $w h$-in-situ (and provide a variety of interesting arguments in its favor). Sauerland, who has independently suggested a similar semantic approach, shows that it can also provide an interpretation for the tail of moved $w h$-phrases/QPs in structures such as (60b) and (63b). In previous 
for present purposes. What is crucial is that there is a not implausible semantic method for interpreting (60b). Assuming this method is secure, we can conclude that general principles of economy prefer (60b) to (60a) since the former is closer to (58). In other words, (60b) involves fewer operations (of deletion) on (58) and is thus preferred. ${ }^{44}$

For QR, similar issues arise. A sentence such as (61) has (62) as the output of QR, which can in turn be converted to one of the structures in (63). ${ }^{45}$ Economy principles determine that the interpreted structure is $(63 \mathrm{~b}) .^{46}$

(61) $\mathrm{John}_{1}$ [v P t likes every boy].

(62) $\mathrm{John}_{1}$ [every boy [v $\mathrm{t}_{1}$ likes every boy]]

(63) a. ${ }^{*} \mathrm{John}_{1}$ [every boy ${ }_{\mathrm{v}} \mathrm{v}_{\mathrm{p}} \mathrm{t}_{1}$ likes $\left.\left.x\right]\right]$ (ruled out by economy)

b. $\operatorname{John}_{1}$ [every boy bvp $_{1}$ likes boy $\left.\left.x\right]\right]$

The inability of QR to obviate Condition $\mathrm{C}$ is explained in the same way as the inability of overt $w h$-movement to do so. The explanation is based on an economy principle that prefers structures in which the restrictor of the quantifier is not eliminated from the base position.

\subsection{The Second Step of the Argument (Fox 1995a)}

With this much in hand, we can proceed to the argument that Condition $\mathrm{C}$ must apply only at LF. The logic of the argument is based on the nature of economy principles. These principles choose an object from a set of competitors (a reference set). If, under certain circumstances, the reference set is restricted so as not to include the most optimal object, it is predicted that an otherwise unacceptable object will be licensed. In the present case it is predicted that (63a) will be licensed under circumstances in which (63b) is not a member of the reference set. Under such circumstances, QR should obviate Condition $\mathrm{C}$ effects. The question is whether such circumstances exist.

In Fox 1995a I suggest that they do. In particular, I suggest that in cases involving antecedentcontained deletion (ACD), the counterpart of (63b) is not licensed and the counterpart of (63a) is the only element in the reference set and hence is acceptable. As is well known, QR is needed in ACD constructions in order for VP-deletion to be licensed (e.g., Sag 1976, May 1985, Kennedy 1997). However, the problem of ACD is solved only if the restrictor is eliminated from the base position. For illustration, take (64) and suppose a theory of VP-ellipsis that involves PF deletion (of the material in angle brackets) licensed by LF Parallelism. If (66a) were the interpreted structure, all would be well; the antecedent VP (in square brackets) would be identical (up to

versions of this article, I assumed that the restrictor at the tail of the chain is interpreted as a predicate that is interpreted via coordination. For reasons of space, I cannot discuss the differences between this proposal and the proposal by Sauerland that I assume here.

${ }^{44}$ For similar though not identical ideas, see Cresti 1996.

${ }^{45} \mathrm{I}$ assume, on the basis of Fox 1995b, that in sentences such as (61) QR is limited to the VP level.

${ }^{46}$ Note that the assumption that economy principles prefer (63b) to (63a) is very similar to the assumption that economy principles prefer feature movement to category movement. On the basis of this similarity, I suggest in Fox 1995a a restatement of the ideas reported here in terms of feature movement. 
alphabetical variance) to the elided VP. If, however, (66b) were the chosen structure, Parallelism would not be obeyed; the antecedent VP would still contain a copy of the elided VP. ${ }^{47}$ For this reason, it is plausible to assume that (66a) is the only element in the reference set and is therefore licensed. $^{48}$

(64) $\mathrm{John}_{1}$

[vp $\mathrm{t}_{1}$ likes every boy Mary does $\langle$ likes $\left.\mathrm{t}\rangle\right]$

(65) $\mathrm{John}_{1}$

[every boy Mary does $\langle$ likes $t\rangle$ [VP $_{P} t_{1}$ likes every boy Mary does $\langle$ likes $\left.t\rangle\right]$ ]

(66) a. John ${ }_{1}$ [every boy Mary does $\langle$ likes $\left.x\rangle\right]_{x}$ [v p $\mathrm{t}_{1}$ likes $\left.x\right]$

b. ${ }^{*} \mathrm{John}_{1}$ [every boy Mary does $\langle$ likes $\left.x\rangle\right]_{x}$ [v Р $\mathrm{t}_{1}$ likes $x$ boy Mary 〈likes $\left.x\right\rangle$ ]

(does not obey Parallelism)

Given these considerations, we predict that QR in ACD constructions will obviate Condition C. In fact, this seems to be the case, as noted by Fiengo and May (1994). ${ }^{49}$ Consider the contrast between (67) and (68). The sentences in (67) end up with the logical forms in (69), which violate Condition C. The sentences in (68), however, involve ACD and thus end up with the logical forms in (70), which do not violate Condition C.

(67) a. ??/*You sent him $_{1}$ the letter that $\mathrm{John}_{1}$ expected you would write.

b. ??/*You introduced him $_{1}$ to everyone $\mathrm{John}_{1}$ wanted you to meet.

c. ??/*You reported him 1 to every cop that $\mathrm{John}_{1}$ was afraid of.

${ }^{47}$ I believe there is good evidence for a theory of ellipsis involving PF deletion. (See Lasnik 1972, Tancredi 1992, Chomsky and Lasnik 1993, Fox 1995b, and Wold 1995.) However, the ideas developed here do not depend on such a theory. They could just as easily be stated in a theory involving LF copying such as that suggested by Williams (1977). Under such a theory, (64b) would be eliminated from the reference set because it would not allow LF copying without an infinite regress problem (May 1985).

${ }^{48}$ A plausible conclusion from Fox 1995b is that Parallelism is not accessible to economy considerations (see Fox, in press). If we put Fox 1995a together with Fox 1995b, the forced conclusion is that Parallelism is not accessible to the economy conditions that determine whether or not QR is to apply. However, it is accessible to the considerations that determine how the output of $\mathrm{QR}$ is to be converted to an operator-variable construction.

${ }^{49}$ Fiengo and May account for this under the assumption that there is an algorithm that determines at what levels of representation Condition C applies. In standard cases the algorithm determines that Condition $\mathrm{C}$ applies at all levels of representation, and in ACD constructions it determines that Condition C applies only at LF. In Fox 1995a I present various arguments against Fiengo and May's proposal. The most direct argument is the observation that the proposed algorithm, which is based on a notion of an index token, predicts that Condition C would apply only at LF in the sentences in (i). In order to account for the ungrammaticality of these sentences, one would need to appeal to the copy theory of movement. Once such an appeal is made, the algorithm is no longer needed, and the conclusion that Condition C applies only at LF is virtually forced. (For an additional argument against Fiengo and May's proposal, see footnote 50.)

(i) a. ${ }^{*} \mathrm{He}_{1}$ introduced his ${ }_{1}$ mother to [QP everyone that $\mathrm{John}_{1}$ liked].

b. I expected him $_{1}$ to introduce his 1 mother to [QP everyone that $\mathrm{John}_{1}$ thought I did] $*\langle$ introduce his mother to $\mathrm{t}\rangle$ 
(68) a. You sent him 1 the letter that $\mathrm{John}_{1}$ expected you would.

b. You introduced $\operatorname{him}_{1}$ to everyone $\mathrm{John}_{1}$ wanted you to. ${ }^{50}$

c. You reported him 1 to every cop that $\mathrm{John}_{1}$ was afraid you would.

(69) a. you [the letter that $\mathrm{John}_{1}$ expected you would write $]_{x}$ [sent him $1 x$ letter that $\mathrm{John}_{1}$ expected you would write]

b. you [everyone that $\mathrm{John}_{1}$ wanted you to meet $]_{x}$ [introduced $\operatorname{him}_{1}$ to $x$ one that $\mathrm{John}_{1}$ wanted you to meet]

c. you [every cop that $\mathrm{John}_{1}$ was afraid of $]_{x}$ [reported him 1 to $x$ cop that $\mathrm{John}_{1}$ was afraid of]

(70) a. you [the letter that $\mathrm{John}_{1}$ expected you would $\langle\operatorname{send}$ him $\left.x\rangle\right]_{x}$ [sent $\left.\operatorname{him}_{1} x\right]$

b. you [everyone that $\mathrm{John}_{1}$ wanted you to $\langle$ introduce him to $\left.x\rangle\right]_{x}$

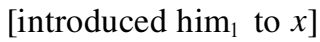

c. you [everyone that $\mathrm{John}_{1}$ was afraid you would $\langle$ report him to $\left.x\rangle\right]_{x}$ [reported $\operatorname{him}_{1}$ to $x$ ]

This line of reasoning makes many additional predictions. To see the nature of these predictions, we must examine the analysis of ambiguous ACD constructions such as (71). This construction is ambiguous with respect to the size of the VP that has been elided (with the two options specified in (71a) and (71b)).

(71) I expected John $n_{1}$ to buy everything that he $e_{1}$ thought I did.

a. 〈bought〉

b. 〈expected him to buy

In addition, there is a potential ambiguity with respect to the relative scope of the universal quantifier and the intensional verb expect. Putting aside Parallelism, (71) is potentially four-ways

${ }^{50}$ Fiengo and May (1994) claim that the sentences in (68) contrast with the sentences in (i), which do not include deletion but are identical in all other respects. All the speakers I have consulted disagree with this judgment.

(i) a. You sent him 1 the letter that $\mathrm{John}_{1}$ expected you would [send him 1 ].

b. You introduced him 1 to everyone $\mathrm{John}_{1}$ wanted you to [introduce him $\mathrm{h}_{1}$ to].

As long as the bracketed VPs in (i) are downstressed, the sentences are acceptable. Since downstressing, just like ellipsis, must obey Parallelism (Tancredi 1992, Rooth 1992), this result is expected under the proposal presented here. However, it is highly problematic for Fiengo and May's proposal. (Thanks to an $L I$ reviewer for stressing the importance of this point.)

Kennedy (1997) discusses the fact that there is no detectable contrast between the examples in (ii).

(ii) a. Polly introduced him $_{1}$ to everyone Erik 1 wanted her to.

b. Polly introduced him 1 to everyone Erik 1 wanted to meet.

In Fox 1995a:116-118 I provide an account of this fact based on the theory of Parallelism for phonological deaccenting. The basic idea is that in (iib), in contrast to the sentences in (67), the embedded VPs can be downstressed (given what Rooth calls "implicational bridging"). When they are downstressed, Parallelism forces the otherwise uneconomical deletion at the tail of the chain. 
ambiguous: the universal quantifier may take scope either below or above the intensional verb expect, and VP-ellipsis may target either the embedded or the matrix VP. Under the copy theory of movement and the assumption that A-movement has an intermediate VP-adjunction step (section 2.2.2), (71) has the four potential LF structures in (72).

(72) a. I expected John 1 to

[QP everything that he ${ }_{1}$ thought I did $\langle$ buy $\left.t\rangle\right]$

buy [QP everything that he ${ }_{1}$ thought I did $\langle$ buy $\left.\mathrm{t}\rangle\right]$

(embedded scope; embedded ellipsis)

b. I expected John 1 to

[QP everything that he ${ }_{1}$ thought I did 〈expected him ${ }_{1}$ to buy $\left.\left.t\right\rangle\right]$

buy [QP everything that he $\mathrm{e}_{1}$ thought I did $\left\langle\right.$ expected him ${ }_{1}$ to buy $\left.\left.\mathrm{t}\right\rangle\right]$

(embedded scope; matrix ellipsis)

c. I

[QP everything that he e $_{1}$ thought I did $\langle$ buy $\left.t\rangle\right]$

expected $\mathrm{John}_{1}$ to

[QP everything that he $e_{1}$ thought I did $\langle$ buy $\left.t\rangle\right]$

buy [QP everything that he $e_{1}$ thought I did $\langle$ buy $\left.t\rangle\right]$

(matrix scope; embedded ellipsis)

d. I

[QP everything that he $e_{1}$ thought I did $\langle$ expected him 1 to buy $\left.t\rangle\right]$

expected $\mathrm{John}_{1}$ to

[QP everything that he $e_{1}$ thought I did $\left\langle\right.$ expected him ${ }_{1}$ to buy $\left.\left.t\right\rangle\right]$

buy [QP everything that he $\mathrm{e}_{1}$ thought I did $\langle$ expected him 1 to buy $\left.t\rangle\right]$

(matrix scope; matrix ellipsis)

However, as pointed out by Larson and May (1990), (72b) has no way of achieving Parallelism. We are thus left with (72a), (72c), and (72d). Each of these must be converted into an operatorvariable construction under the economy principle that minimizes deletion of copies. This economy principle chooses the most optimal operator-variable construction that obeys Parallelism. We thus end up with the three structures in (73).

(73) a. I expected John 1 to

[QP everything that he ${ }_{1}$ thought I did $\langle$ buy $\left.t\rangle\right]$

buy $\mathrm{t}$

(embedded scope; embedded ellipsis)

b. I

[QP everything that he ${ }_{1}$ thought I did $\langle$ buy $\left.t\rangle\right]_{x}$

expected $\mathrm{John}_{1}$ to

[QP $x$ thing that he ${ }_{1}$ thought I did $\langle$ buy $\left.\mathrm{t}\rangle\right]$

buy $\mathrm{t}$

(matrix scope; embedded ellipsis) 
c. I

[QP everything that he $e_{1}$ thought I did $\left\langle\right.$ expected him ${ }_{1}$ to buy $\left.\left.t\right\rangle\right]$ expected $\mathrm{John}_{1}$ to buy $\mathrm{t}$

(matrix scope; matrix ellipsis)

In (73) there is a single instance of QR, hence a single chain; in (73b) and (73c) there are two chains. In all three constructions Parallelism forces a simple trace at the $\theta$-position. (73b) and (73c) differ in that Parallelism requires the elimination of the intermediate trace in the former but not in the latter.

Now consider (74). This sentence differs from (71) in that it allows only matrix VP-ellipsis. This is exactly what is predicted; structures (75a) and (75b), which involve embedded VP-deletion, violate Condition $\mathrm{C}$, whereas structure $(75 \mathrm{c})$ does not.

(74) I expected him 1 to buy everything that $\mathrm{John}_{1}$ thought I did.

a. *〈bought $\mathrm{t}\rangle$

b. 〈expected him 1 to buy $\mathrm{t}\rangle$

(75) a. I expected him to

[QP everything that John ${ }_{1}$ thought I did $\langle$ buy $\left.t\rangle\right]$ buy $\mathrm{t}$

(embedded scope; embedded ellipsis)

b. I

[QP everything that $\mathrm{John}_{1}$ thought I did $\langle$ buy $\left.\mathrm{t}\rangle\right]_{x}$

expected $\operatorname{him}_{1}$ to

[Q $x$ thing that $\mathrm{John}_{1}$ thought I did $\langle$ buy $\mathrm{t}\rangle$ ]

buy $\mathrm{t}$

(matrix scope; embedded ellipsis)

c. I

[QP everything that $\mathrm{John}_{1}$ thought I did $\left\langle\right.$ expected him ${ }_{1}$ to buy $\left.\mathrm{t}\right\rangle$ ] expected $\operatorname{him}_{1}$ to buy $\mathrm{t}$

(matrix scope; matrix ellipsis)

The proposal predicts that $\mathrm{QR}$ would bleed Condition C only if the $\mathrm{QR}$ is long enough to get out of the c-command domain of the "dangerous" pronoun, and only if the QR is needed for ACD resolution and thus requires elimination of the offending material at the tail of the chain.

Additional examples demonstrate that this prediction is correct. Consider the contrast between (76) and (77). (76) is ambiguous. (77) requires matrix VP-deletion. Once again, this is predicted; only matrix VP-deletion forces the less economical structure that avoids a Condition $\mathrm{C}$ violation.

(76) In the end, I demanded that $\mathrm{John}_{1}$ read exactly those books that he ${ }_{1}$ suspected I would.

a. 〈read $\mathrm{t}\rangle$

b. 〈demand that he read $\mathrm{t}\rangle$ 


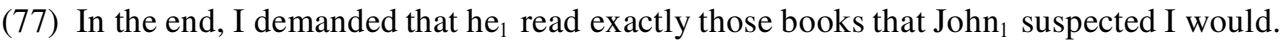
a. $*\langle$ read $\mathrm{t}\rangle$

b. 〈demand that he read $\mathrm{t}\rangle$

Now consider the contrast between (78) and (79). In (78) embedded VP-deletion is preferred to matrix VP-deletion (for some speakers, the latter is impossible). In (79), where embedded VPdeletion would bring about a Condition $\mathrm{C}$ effect, the judgments are reversed. ${ }^{51}$

(78) I said that Bill ${ }_{1}$ bought everything he ${ }_{1}$ thought I did.

a. 〈bought $\mathrm{t}$ 〉

b. ?〈said that he bought $\mathrm{t}\rangle$

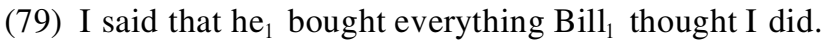

a. *〈bought $\mathrm{t}\rangle$

b. ?〈said that he bought $\mathrm{t}\rangle$

In sections 2 and 3 I showed that scope reconstruction feeds Condition $C$. This forces the conclusion that binding theory applies (also) at LF. In this section I have shown that (a) it is possible to maintain that Condition $\mathrm{C}$ applies only at LF despite what appears to be evidence to the contrary (Chomsky 1993) and (b) this stance is virtually necessary on empirical grounds (Fox 1995a).

\section{Scope Reconstruction in A-Chains}

As shown in section 5, under normal circumstances A-movement fails to affect Condition C irrespective of whether or not the moved constituent is reconstructed. This means that under normal circumstances we do not expect $\bar{A}$-movement to show an interesting correlation between scope reconstruction and Condition $\mathrm{C}$. This might raise a question regarding the status of the correlation discussed in section 2. The answer is simple: normal cases of A-movement do not affect Condition $\mathrm{C}$ irrespective of reconstruction. When reconstruction takes place, the " abnormal', cases of A-movement behave like the normal cases. In other words, the method that allows A-movement to affect Condition $\mathrm{C}$ does not allow for reconstruction. Let us see how this result follows from the view of syntactic reconstruction that the copy theory of movement provides.

Under the copy theory of movement, A-movement can affect Condition $\mathrm{C}$ only if the r-expression is within an adjunct and only if the adjunct is inserted after movement. This is illustrated schematically in (80) and (81).

${ }^{51}$ The (a) readings require focal stress on the pronoun $I$. This should follow from independent principles (see Rooth 1992). As David Pesetsky (personal communication) points out, it might be more accurate to state the correlation as a correlation between focal stress and Condition $\mathrm{C}$, which is explained by the proposal I make together with an independently motivated correlation between the size of ellipsis and the site of focal stress. 
(80) $*\left[\right.$ Q P . . [ complement . . r-expression cox $\left.\left._{1} \ldots\right] \ldots\right]_{2}$

$$
\ldots \operatorname{pronoun}_{1} \ldots[\mathrm{Q} \text { P } \ldots[\text { complement } \ldots \text {.r-expression } 1 \ldots] \ldots]_{2}
$$

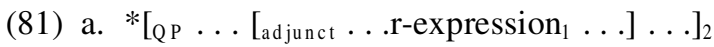

$$
\ldots \operatorname{pronoun}_{1} \ldots[\mathrm{Q} \text { P } \ldots[\text { adjunct } \ldots . \text { r-expression } 1 \ldots] \ldots]_{2}
$$

(adjunct inserted before movement)

b. $\left[\mathrm{Q} P \ldots\right.$ adjunct $\ldots$.r-expression $\left.\left._{1} \ldots\right] \ldots\right]_{2}$

$$
\ldots \operatorname{pronoun}_{1} \ldots[\mathrm{QP} \ldots]_{2}
$$

(adjunct inserted after movement)

Reconstruction, on the other hand, is achieved via deletion of the head of the chain and interpretation of the tail alone, as in (82).

$$
\mathrm{QP}_{2} \ldots \text { pronoun }_{1} \ldots \mathrm{QP}_{2} \mathrm{MPMIMIMN}_{\text {reconstruction }} \ldots \operatorname{pronoun}_{1} \ldots \mathrm{QP}_{2}
$$

If an adjunct is inserted after movement, reconstruction is blocked since it will not allow the adjunct to be interpreted. ${ }^{52}$ It thus follows that $\bar{A}$-movement cannot affect Condition $\mathrm{C}$ when the moved constituent is reconstructed.

This explanation is based on the idea that the moved constituent is fully reconstructed. However, the cases of $w h$-movement discussed in section 2 involve forms of partial reconstruction; in these cases the wh-operator is interpreted in the surface position and only a part of it is reconstructed to the base position. I would like to show that all these cases nevertheless involve reconstruction of a constituent that includes the adjunct and thus are captured by the explanation given above. Furthermore, I would like to show a case of partial reconstruction that does not necessarily include the adjunct. In this case the copy theory of movement predicts that Condition $\mathrm{C}$ would be violated if and only if the adjunct that contains the r-expression is reconstructed. ${ }^{53}$

\subsection{The Cases Discussed in Section 2}

In section 2 I discussed two basic cases of reconstruction. Let us begin with the simple case discussed in sections 2.2 and 2.3. In this case a relative clause contains a variable that must be bound in the reconstructed position. If the relative clause contains an r-expression as well and if the r-expression is bound in the reconstructed position, a Condition $\mathrm{C}$ effect emerges. ${ }^{54}$

(83) *[Which book that he 1 asked Ms. Brown 2 for] did she ${ }_{2}$ give every student ?

\footnotetext{
52 There are many ways to capture the idea that unrecoverable deletion of the adjunct is blocked. One possibility is that an element can be deleted only under identity with a copy. Late insertion of an adjunct makes the head of the chain nonidentical to the tail.

53 This prediction would follow under any syntactic account of partial reconstruction.

${ }^{54}$ Similar considerations apply to the cases of unselective binding in which the relative clause contains a variable bound in the base position by an adverb of quantification (section 2.3).
} 
This case follows straightforwardly from the copy theory of movement. If the adjunct is inserted after movement, there is no way for the variable to be bound. For concreteness, let us assume, following Engdahl (1980), that (83) has the following LF structure:

(84) which (choice function) $\mathrm{f}$ did $\mathrm{she}_{2}$ give every student $\mathrm{f}$ (book that he ${ }_{1}$ asked Ms. Brown ${ }_{2}$ for)

This LF structure has the adjunct in the base position and thus cannot result from its late insertion. Now let us look at the slightly more complex case that was discussed in section 2.1 . In this case a how many question is separated, how being interpreted in the surface position and many $N P$ being reconstructed to the base position.

(85) How many ideas is John likely to come up with?

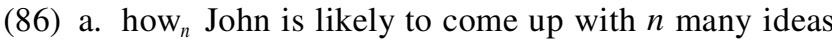

b. what is the number $n$ such that

John is likely to come up with $n$ many ideas

In (85) the creation verb come up with requires reconstruction. As shown in section 2.1, this reconstruction brings about a Condition $\mathrm{C}$ effect even when an r-expression is contained within an adjunct.

(87) *[How many ideas related to John's $s_{1}$ theory]

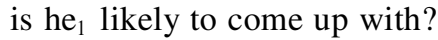

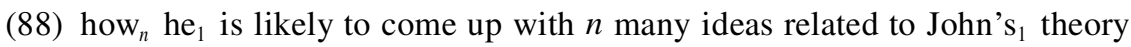

Once again, the reason for this is straightforward. The adjunct must modify the NP ideas. If the DP many ideas is deleted from the surface position and interpreted at the base position (if it is reconstructed), the adjunct must be in the base position as well. ${ }^{55}$

55 An $L I$ reviewer raises the following question: under the copy theory of movement shouldn't (87) be expected to have the LF structure in (i) and shouldn't this structure obviate Condition C?

(i) how $n$ [n many ideas related to John's ${ }_{1}$ theory] is he ${ }_{1}$ likely to come up with [ $n$ ideas]

In fact, the question goes beyond Condition C. The LF structures suggested by the reviewer must be ruled out for independent reasons. Thus, a sentence such as How many ideas related to his theory is John planning to come up with? does not have the following LF structure:

(ii) how $_{n}\left[n\right.$ many ideas related to his ${ }_{1}$ theory] is $\mathrm{John}_{1}$ likely to come up with [ $n$ ideas]

what is the number $n$ such that there are $n$ many ideas related to his $s_{1}$ theory and $\mathrm{John}_{1}$ is likely to come up with [ $n$ ideas]

The putative LF structure would have a rather bizarre meaning in which what is questioned is the number of ideas that John is planning to come up with (rather than the number of ideas of the type determined by the relative clause).

As mentioned in section 2, I follow the standard assumption that the wh-phrase how many NP has two parts. One 


\subsection{A Case of Partial Reconstruction That Does Not Need to Include the Adjunct}

Consider the following how many question:

(89) [How many more ideas than what's needed for his ${ }_{1}$ tenure] is $\mathrm{John}_{1}$ planning to come up with?

This question is similar to (85) in that the semantics of the embedded creation verb force reconstruction of the DP $N$ many ideas. However, unlike (85), (89) is ambiguous with respect to the scopal position of the comparative quantifier. This ambiguity is represented by the two LF structures in (90).

(90) a. $\operatorname{how}_{n}(\exists N) N$ is $n$-more than ( $\left.1 M\right)$ [ $M$ many ideas are needed for his ${ }_{1}$ tenure] [ $\mathrm{John}_{1}$ is planning to come up with $N$ many ideas]

(answer given (S5): 60)

b. how $\mathrm{John}_{1}$ is planning

$(\exists N) N$ is $n$-more than $(1 M)$ [ $M$ many ideas are needed for his ${ }_{1}$ tenure]

$\left[\mathrm{PRO}_{1}\right.$ to come up with $N$ many ideas]

(answer given (S5): 10)

To see this ambiguity, consider the following situation:

(S5) John thinks that he needs 100 ideas for tenure. He wants to come up with 110 ideas to be on the safe side (that is to say, he wants to have 10 more ideas than what's needed). However, the truth is that he needs only 50 ideas for tenure.

Given (S5), there are two possible answers to (89): 60 and 10. These two answers correspond to the two LF structures in (90). If the comparative takes wide scope relative to the intensional verb plan, the value of the definite description $(1 M)$ [M many ideas are needed for his $s_{1}$ tenure $]$ is determined in the actual world to be 50 and the answer to the question is 60 . If, on the other hand, the comparative takes narrow scope relative to the intensional verb, the value of the definite description is determined in the belief worlds to be 100 and the answer to the question is 10 .

(89) differs from (85) in that in (89) there is an adjunct, what's needed for his tenure, that is not contained within the DP many ideas. Therefore, in (89) it is possible to reconstruct the DP

part consists of the wh-word how (which could be paraphrased as what n); the other consists of the DP many NP, which is a quantifier that ranges over individuals.

(iii) [how many NP $]_{1} \phi\left(\mathrm{t}_{1}\right)$ how $_{n} n$ many NP $\lambda x \phi(x)$

Under this assumption, the LF structure in (ii) must be altered as follows:

(iv) how $_{n}\left[n\right.$ many ideas related to his ${ }_{1}$ theory $] \lambda x$

is $\mathrm{John}_{1}$ likely to come up with [ $n$ ideas]

This structure violates the constraint against vacuous quantification ( $\lambda x$ does not bind a variable). If we replace $n$ ideas with $x$ ideas, we get rid of vacuous quantification. However, now the LF structure has the wide scope reading, which is expected and in fact does obviate Condition $\mathrm{C}$. 
without reconstructing the adjunct. We thus predict that (89) can be transformed into (91) without yielding a Condition $\mathrm{C}$ effect. This prediction is borne out. Furthermore, it is fairly clear that (91) has only one answer-60-given the situation described in (S5). In other words, it seems that (91) has only the LF structure (92), in which the adjunct is inserted after movement. ${ }^{56}$

(91) [How many more ideas than what's needed for John's $s_{1}$ tenure]

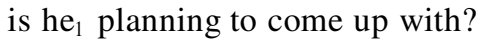

(92) a. $\operatorname{how}_{n}(\exists N) N$ is $n$-more than $(M M)$ [ $M$ many ideas are needed for John's ${ }_{1}$ tenure] [he $_{1}$ is planning to come up with $N$ many ideas]

(answer given (S5): 60)

b. how $_{n}$ he 1 is planning

$(\exists N) N$ is $n$-more than $(1 M)$ [ $M$ many ideas are needed for John's $s_{1}$ tenure $]$ $\left[\mathrm{PRO}_{1}\right.$ to come up with $N$ many ideas]

(answer given (S5): 10)

In this section we have seen that in cases of partial reconstruction late insertion of an adjunct is possible if and only if the adjunct is not contained in the reconstructed material. This result is exactly as expected under the copy theory of movement. Furthermore, it strengthens the idea that reconstruction is syntactic. It shows that when there is partial reconstruction, syntactic effects are found for exactly those elements that are reconstructed.

\section{A Note on the A/A Distinction}

The conclusion that scope reconstruction feeds Condition $\mathrm{C}$ (sections 2 and 3 ) is true for all types of movement. However, the conclusion that movement bleeds Condition $\mathrm{C}$ only when there is reason to get rid of the restrictor (section 5) is true only with respect to A-movement. A-movement bleeds Condition $\mathrm{C}$ with no special proviso. This well-known contrast is illustrated in (93) and (94).

(93) Standard A-movement fails to bleed Condition $C$

a. ??/*Which argument that $\mathrm{John}_{1}$ is a genius did he $\mathrm{e}_{1}$ believe $\mathrm{t}$ ?

b. $*$ A different person told him $_{1}$ about every argument that $\mathrm{John}_{1}$ is a genius.

(94) Standard A-movement bleeds Condition C

Every argument that $\mathrm{John}_{1}$ is a genius seems to $\operatorname{him}_{1}$ to be flawless.

I do not fully understand this contrast. Nevertheless, I will state it explicitly in the following manner:

(95) a. A-movement (optionally) leaves a simple trace.

b. A-movement obligatorily leaves a copy that is converted to an operator-variable construction in accordance with economy considerations.

56 This analysis would apply also to similar examples that were problematic for Heycock's account (Heycock 1995: fn. 19). Thanks to Chris Kennedy for bringing these examples to my attention. 
Given this distinction, is it plausible to assume that A-reconstruction is the result of the same mechanism that was proposed for $\bar{A}$-movement in section 6? As far as I can see, there are two possibilities. One is that A-movement is incapable of leaving a copy at the tail of the chain and must therefore resort to another scope-shifting operation such as QL. ${ }^{57}$ The other is that Amovement can optionally leave a copy and that when it does, scope reconstruction is available. In any event, scope reconstruction is reflected in the syntax and the results of section 3 are predicted.

For presentational purposes, I assume that QL is necessary for A-reconstruction. The possible LF structures that are derived from the two types of movement are sketched in (96) and (97).

(96) Scope reconstruction in A-movement

SS: Someone [that she knows] is likely [t to win the lottery].

$\mathrm{LF}_{1}$ : someone [that she knows] is likely [t to win the lottery]

$\mathrm{LF}_{2}$ : is likely [someone [that she knows]

[t to win the lottery]]

(97) Scope reconstruction in A-movement

$\mathrm{SS}_{1}$ : $\quad$ how many people [that she knows]

is Mary likely to hire how many people [that she knows]

(adjunct inserted before movement)

$\mathrm{LF}_{1,1}: \quad$ how $_{n}$

is Mary likely to hire $n$ many people [that she knows]

$\mathrm{LF}_{1,2}$ : $\operatorname{how}_{n} n$ many people [that she knows]

is Mary likely to hire $x$ people [that she knows]

$\mathrm{SS}_{2}$ : $\quad$ how many people [that she knows]

is Mary likely to hire how many people

(adjunct inserted after movement)

$\mathrm{LF}_{2}$ : $\operatorname{how}_{n} n$ many people [that she knows]

is Mary likely to hire $x$ people

For A-movement, there are one S-Structure representation and two LF representations that differ depending on whether or not QL takes place. The latter yields what I have called scope reconstruction and has the consequences I have discussed for Condition $\mathrm{C}$ (section 3). For $\bar{A}$ movement, there are two S-Structure representations that differ depending on whether the adjunct is inserted before or after movement. Only $\mathrm{SS}_{2}$ can bleed Condition C. However, only $\mathrm{SS}_{1}$ can bring about scope reconstruction (hence the consequences in section 2). ${ }^{58}$

${ }^{57}$ For an argument in favor of this possibility, see Chomsky 1995. As pointed out by David Pesetsky and Irene Heim (personal communications), the necessary stipulation about A-movement could be derived from an assumption that has an air of explanation to it, namely, the assumption that copies must receive Case.

${ }^{58} \mathrm{SS}_{2}$ has only one LF structure, in which many has wide scope. $\mathrm{SS}_{1}$ has two LF structures, which differ in the scope they assign to many. 


\section{Conclusions}

In this article I have presented evidence that the predictions of Condition $\mathrm{C}$ come out right only if we assume that this condition applies to the structures that are interpreted. On the one hand, (if QL exists) Condition C must "see" the output of this LF operation (section 3). On the other hand, Condition C does not see the S-Structure input to the LF operation of QR (section 5). The reason it looks as though Condition $\mathrm{C}$ inspects a pre- $\mathrm{QR}$ structure relates to a special property of A-chains: movement leaves a copy that can be eliminated only when necessary (under ACD). This special property provides a syntactic account of A-reconstruction (section 6), which in turn accounts for the correlation with Condition $\mathrm{C}$ (section 2). Reconstruction may work differently for A- and A-movement. Nevertheless, in both cases it is reflected at LF. For this reason, the semantic mechanism of type lifting must be restricted (section 4).

\section{References}

Aoun, Joseph. 1982. On the logical nature of the binding principles: Quantifier lowering, double raising of there and the notion empty element. In Proceedings of NELS 12, 16-36. GLSA, University of Massachusetts, Amherst.

Aoun, Joseph, and Yen-hui Audrey Li. 1993. Syntax of scope. Cambridge, Mass.: MIT Press.

Beck, Sigrid. 1996. Wh-construction and transparent Logical Form. Doctoral dissertation, Universität Tübingen.

Beghelli, Filippo. 1993. A minimalist approach to quantifier scope. In NELS 23, 65-80. GLSA, University of Massachusetts, Amherst.

Beghelli, Filippo, and Tim Stowell. 1995. The direction of quantifier movement. Ms., UCLA, Los Angeles, Calif.

Chierchia, Gennaro. 1995a. Dynamics of meaning: Anaphora, presupposition, and the theory of grammar. Chicago: University of Chicago Press.

Chierchia, Gennaro. 1995b. Individual-level predicates as inherent generics. In The generic book, ed. Greg N. Carlson and Francis J. Pelletier, 176-223. Chicago: University of Chicago Press.

Chomsky, Noam. 1957. Syntactic structures. The Hague: Mouton.

Chomsky, Noam. 1977. Essays on form and interpretation. Amsterdam: Elsevier North-Holland.

Chomsky, Noam. 1981. Lectures on government and binding. Dordrecht: Foris.

Chomsky, Noam. 1986a. Barriers. Cambridge, Mass.: MIT Press.

Chomsky, Noam. 1986b. Knowledge of language: Its nature, origin, and use. New York: Praeger.

Chomsky, Noam. 1993. A minimalist program for linguistic theory. In The view from Building 20: Essays on linguistics in honor of Sylvain Bromberger, ed. Kenneth Hale and Samuel Jay Keyser, 1-52. Cambridge, Mass.: MIT Press.

Chomsky, Noam. 1995. Categories and transformations. In The Minimalist Program, 219-394. Cambridge, Mass.: MIT Press.

Chomsky, Noam, and Howard Lasnik. 1993. The theory of principles and parameters. In Syntax: An international handbook of contemporary research, ed. Joachim Jacobs, Arnim von Stechow, Wolfgang Sternefeld, and Theo Vennemann, 506-569. Berlin: Walter de Gruyter.

Cinque, Guglielmo. 1990. Types of A-dependencies. Cambridge, Mass.: MIT Press.

Cresti, Diana. 1995. Extraction and reconstruction. Natural Language Semantics 3:79-122.

Cresti, Diana. 1996. Economy and the scope of amount phrases. In Proceedings of the $14^{\text {th }}$ West Coast Conference on Formal Linguistics, 79-94. Stanford, Calif.: CSLI Publications. [Distributed by Cambridge University Press.] 
Engdahl, Elisabet. 1980. The syntax and semantics of questions in Swedish. Doctoral dissertation, University of Massachusetts, Amherst.

Engdahl, Elisabet. 1986. Constituent questions: The syntax and semantics of questions with special reference to Swedish. Dordrecht: Reidel.

Fiengo, Robert, and Robert May. 1994. Indices and identity. Cambridge, Mass.: MIT Press.

Fox, Danny. 1995a. Condition C effects in ACD. In MIT working papers in linguistics 27: Papers on minimalist syntax, 105-120. MITWPL, Department of Linguistics and Philosophy, MIT, Cambridge, Mass.

Fox, Danny. 1995b. Economy and scope. Natural Language Semantics 3:283-341.

Fox, Danny. In press. Economy and semantic interpretation. Cambridge, Mass.: MIT Press and MITWPL. Frampton, John. 1991. Relativized Minimality: A review. The Linguistic Review 8:1-46.

Freidin, Robert. 1986. Fundamental issues in the theory of binding. In Studies in the acquisition of anaphora, ed. Barbara Lust, 151-188. Dordrecht: Reidel.

Frey, Werner. 1989. Syntaktische Bedingungen für die Interpretation. Doctoral dissertation, Universität Stuttgart.

Grodzinsky, Yosef, and Tanya Reinhart. 1993. The innateness of binding and coreference. Linguistic Inquiry 24:69-102.

Heim, Irene. 1987. Where does the definiteness restriction apply? In The representation of (in)definiteness, ed. Eric Reuland and Alice G. B. ter Meulen, 21-42. Cambridge, Mass.: MIT Press.

Heim, Irene, and Angelika Kratzer. Forthcoming. Semantics in generative grammar. Oxford: Blackwell.

Heycock, Caroline. 1995. Asymmetries in reconstruction. Linguistic Inquiry 26:547-570.

Higginbotham, James. 1983. Logical Form, binding, and nominals. Linguistic Inquiry 14:395-420.

Hoji, Hajime. 1985. Logical Form constraints and configurational structure in Japanese. Doctoral dissertation, University of Washington, Seattle.

Hornstein, Norbert. 1995. Logical Form: From GB to Minimalism. Oxford: Blackwell.

Jackendoff, Ray. 1972. Semantic interpretation in generative grammar. Cambridge, Mass.: MIT Press.

Kennedy, Christopher. 1997. Antecedent-contained deletion and the syntax of quantification. Linguistic Inquiry 28:662-688.

Kitahara, Hisatsugu. 1994. Raising quantifiers without quantifier raising. Ms., Harvard University, Cambridge, Mass.

Kratzer, Angelika. 1995. Stage-level and individual-level predicates. In The generic book, ed. Greg N. Carlson and Francis J. Pelletier, 125-175. Chicago: University of Chicago Press.

Kratzer, Angelika. 1998. Scope or pseudo scope? Are there wide scope indefinites? In Events in grammar, ed. Susan Rothstein, 163-196. Dordrecht: Kluwer.

Krifka, Manfred. 1998. Scope inversion under the rise-fall contour in German. Linguistic Inquiry 29:75-112. Larson, Richard, and Robert May. 1990. Antecedent containment or vacuous movement: Reply to Baltin. Linguistic Inquiry 21:103-122.

Lasnik, Howard. 1972. Analyses of negation in English. Doctoral dissertation, MIT, Cambridge, Mass.

Lasnik, Howard. 1976. Remarks on coreference. Linguistic Analysis 2:1-22.

Lebeaux, David. 1988. Language acquisition and the form of the grammar. Doctoral dissertation, University of Massachusetts, Amherst.

Lebeaux, David. 1990. Relative clauses, licensing and the nature of the derivation. In Proceedings of NELS 20, 318-332. GLSA, University of Massachusetts, Amherst.

Lebeaux, David. 1994. Where does binding theory apply? Ms., University of Maryland, College Park.

Liu, Feng-Hsi. 1990. Scope dependency in English and Chinese. Doctoral dissertation, UCLA, Los Angeles, Calif.

Longobardi, Giuseppe. 1987. Extraction from NP and the proper notion of head government. In The syntax of noun phrases, ed. Alessandra Giorgi and Giuseppe Longobardi, 57-112. Cambridge: Cambridge University Press. 
May, Robert. 1977. The grammar of quantification. Doctoral dissertation, MIT, Cambridge, Mass.

May, Robert. 1985. Logical Form: Its structure and derivation. Cambridge, Mass.: MIT Press.

McCawley, James D. 1988. The syntactic phenomena of English. Chicago: University of Chicago Press.

Nissenbaum, Jon. Forthcoming. Movement and derived predicates:Evidence from parasitic gaps. In Proceedings of the $17^{\text {th }}$ West Coast Conference on Formal Linguistics.

Reinhart, Tanya. 1995. Interface strategies. OTS, Universiteit Utrecht.

Riemsdijk, Henk van, and Edwin Williams. 1981. NP-Structure. The Linguistic Review 1:171-217.

Rizzi, Luigi. 1990. Relativized Minimality. Cambridge, Mass.: MIT Press.

Romero, Maribel. 1996. The (cor)relation between scope reconstruction and connectivity effects. Ms., University of Massachusetts, Amherst.

Rooth, Mats. 1992. Ellipsis redundancy and reduction redundancy. In Proceedings of the Stuttgart Ellipsis Workshop, ed. Steve Berman and Arild Hestvik. (Arbeitspapiere des Sonderforschungsbereichs 340, Bericht Nr. 29.) IBM Germany, Heidelberg.

Rullman, Hotze. 1995. Maximality in the semantics of wh-constructions. Doctoral dissertation, MIT, Cambridge, Mass.

Rullman, Hotze, and Sigrid Beck. 1998. Reconstruction and the interpretation of which-phrases. In Reconstruction: Proceedings of the 1997 Tübingen Workshop, 223-256. (Arbeitspapiere des Sonderforschungsbereichs 340, Bericht Nr. 127.) Universität Stuttgart and Universität Tübingen.

Sag, Ivan. 1976. Deletion and Logical Form. Doctoral dissertation, MIT, Cambridge, Mass.

Sauerland, Uli. In progress. The making and meaning of chains. Doctoral dissertation, MIT, Cambridge, Mass.

Schütze, Carson. 1995. PP attachment and agreement. In MIT working papers in linguistics 26: Papers on language processing and acquisition, 95-152. MITWPL, Department of Linguistics and Philosophy, MIT, Cambridge, Mass.

Sharvit, Yael. 1997. The syntax and semantics of functional relative clauses. Doctoral dissertation, Rutgers University, New Brunswick, N.J.

Sportiche, Dominique. 1996. A-reconstruction and constituent structure. Handout of talk given at Université du Québec à Montréal, October 1996.

Sternefeld, Wolfgang. 1997. Fancy binding. Ms., Universität Tübingen.

Tada, Hiroaki. 1993. A/A-bar partition in derivation. Doctoral dissertation, MIT, Cambridge, Mass.

Tancredi, Chris. 1992. Deletion, deaccenting and presupposition. Doctoral dissertation, MIT, Cambridge, Mass.

Williams, Edwin. 1977. Discourse and Logical Form. Linguistic Inquiry 8:101-139.

Williams, Edwin. 1985. PRO in NP. Natural Language \& Linguistic Theory 3:277-295.

Williams, Edwin. 1987. Implicit arguments, the binding theory, and control. Natural Language \& Linguistic Theory 5:151-180.

Winter, Yoad. 1995. On the formalization of choice functions as representing the scope of indefinites. In Formal grammar, ed. Glyn V. Morrill and Richard T. Oehrle, 275-290. (Proceedings of the Conference of the European Summer School in Logic, Language, and Information.) Universitat Politécnica de Catalunya, Barcelona.

Wold, Dag. 1995. Identity in ellipsis: Focal structure and phonetic deletion. Ms., MIT, Cambridge, Mass.

\section{Harvard University}

Society of Fellows

$78 \mathrm{Mt}$. Auburn Street

Cambridge, Massachusetts 02138

djfox@fas.harvard.ed 